International Center for Public Policy

Working Paper 12-08

February 2012

\title{
Estimating the Impacts of Bolivia's Protected Areas on Poverty
}

Gustavo Canavire-Bacarreza

Merlin M. Hanauer

ANDREWYOUNG SCHOOL

GeorgaState University 



\title{
International Center for Public Policy \\ Working Paper 12-08
}

\section{Estimating the Impacts of Bolivia's Protected Areas on Poverty}

\author{
Gustavo Canavire-Bacarreza \\ Merlin M. Hanauer
}

February 2012

International Center for Public Policy

Andrew Young School of Policy Studies

Georgia State University

Atlanta, Georgia 30303

United States of America

Phone: (404) 651-1144

Fax: (404) 651-4449

Email: hseraphin@gsu.edu

Internet: http://aysps.gsu.edu/isp/index.html

Copyright 2006, the Andrew Young School of Policy Studies, Georgia State University. No part of the material protected by this copyright notice may be reproduced or utilized in any form or by any means without prior written permission from the copyright owner. 


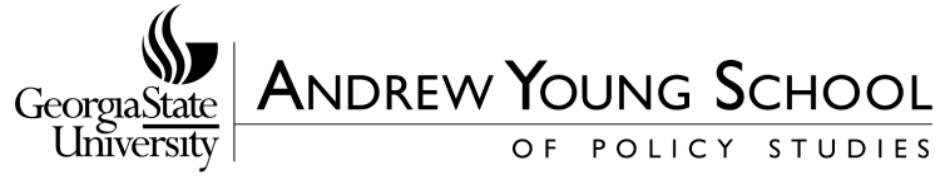

\section{International Center for Public Policy Andrew Young School of Policy Studies}

The Andrew Young School of Policy Studies was established at Georgia State University with the objective of promoting excellence in the design, implementation, and evaluation of public policy. In addition to two academic departments (economics and public administration), the Andrew Young School houses seven leading research centers and policy programs, including the International Center for Public Policy.

The mission of the International Center for Public Policy is to provide academic and professional training, applied research, and technical assistance in support of sound public policy and sustainable economic growth in developing and transitional economies.

The International Center for Public Policy at the Andrew Young School of Policy Studies is recognized worldwide for its efforts in support of economic and public policy reforms through technical assistance and training around the world. This reputation has been built serving a diverse client base, including the World Bank, the U.S. Agency for International Development (USAID), the United Nations Development Programme (UNDP), finance ministries, government organizations, legislative bodies and private sector institutions.

The success of the International Center for Public Policy reflects the breadth and depth of the in-house technical expertise that the International Center for Public Policy can draw upon. The Andrew Young School's faculty are leading experts in economics and public policy and have authored books, published in major academic and technical journals, and have extensive experience in designing and implementing technical assistance and training programs. Andrew Young School faculty have been active in policy reform in over 40 countries around the world. Our technical assistance strategy is not to merely provide technical prescriptions for policy reform, but to engage in a collaborative effort with the host government and donor agency to identify and analyze the issues at hand, arrive at policy solutions and implement reforms.

The International Center for Public Policy specializes in four broad policy areas:

- Fiscal policy, including tax reforms, public expenditure reviews, tax administration reform

- Fiscal decentralization, including fiscal decentralization reforms, design of intergovernmental transfer systems, urban government finance

- Budgeting and fiscal management, including local government budgeting, performancebased budgeting, capital budgeting, multi-year budgeting

- Economic analysis and revenue forecasting, including micro-simulation, time series forecasting,

For more information about our technical assistance activities and training programs, please visit our website at http://aysps.gsu.edu/isp/index.html or contact us by email at hseraphin@gsu.edu. 


\title{
Estimating the Impacts of Bolivia's Protected Areas on Poverty*
}

\author{
Gustavo Canavire-Bacarreza ${ }^{\dagger} \quad$ Merlin M. Hanauer ${ }^{\ddagger}$
}

February, 2012

\begin{abstract}
Protected areas represent a powerful policy tool for the preservation of ecosystems and their services. The rapid proliferation of protected areas in Bolivia over the past several decades has prompted interest in understanding their impacts on surrounding populations. Recent studies from other developing countries show that protected areas have had positive impacts on poverty. Using rich biophysical and socioeconomic data from Bolivia we find that municipalities with at least $10 \%$ of their area occupied by a protected area established between 1992 and 2000 exhibited differentially greater levels of poverty reduction between 1992 and 2001 compared to similar municipalities unaffected by protected areas. We find that our results are robust to a number of econometric specifications, spillover analyses and a placebo study. Although our overarching results that Bolivia's protected areas were associated with poverty reduction are similar to previous studies, our underlying results differ subtly, but significantly. Previous studies found that controlling for key observable covariates led to fundamentally antithetical results compared to naïve (uncontrolled) estimates. Conversely, our results indicate that naïve estimates lead to an over estimation of the poverty reducing impacts of protected areas. Our results expose the heterogeneity of protected area impacts across countries and, therefore, underscore the importance of country-level impact evaluations in order to build the global knowledge base regarding the socioeconomic impacts of protected areas.
\end{abstract}

Key words: ecosystems, poverty, protected areas, impacts, program evaluation, econometrics, Bolivia

*Funding for this study comes from the Latin American and Caribbean Environmental Economics Program (LACEEP), Small Grants Program for Research in Environmental Economics. We would like to thank Andrew Balthrop, Allen Blackman, Mario Boudoin, Salvatore Di Falco, Paul J. Ferraro, Alfonso Malky, Juan Robalino and the participants at the LACEEP seminars in Costa Rica for helpful comments and suggestions. We extend deep gratitude to Juan Carlos Ledezma for providing and discussing data.

${ }^{\dagger}$ International Center for Public Policy, Andrew Young School of Policy Studies, Georgia State University, PO Box 3992, Atlanta, GA 30302-3992, USA; gcanavirebacarreza@gsu.edu

${ }^{\ddagger}$ Department of Economics, Sonoma State University, 1801 East Cotati Avenue, Rohnert Park, CA 94928, USA; hanauer@sonoma.edu 


\section{Introduction}

Protected areas are an important tool for the global conservation of ecosystems and biodiversity (MEA, 2005). Presently, approximately $13 \%$ of the world's terrestrial surface is covered by some form of protected area (WDPA, 2011). The sheer scale of the global coverage of protected areas highlights the importance of understanding their underlying impacts. Unfortunately, there is little empirical evidence on the environmental impacts of protected areas and even less on the socioeconomic impacts of protected areas on surrounding communities (Coad et al., 2008). The socioeconomic implications of establishing protected areas are of particular interest given the high degree of overlap between areas of remaining biodiversity (i.e., areas likely to be targeted for protection) and poverty (Sachs et al., 2009). This raises concerns from poverty advocates that achieving environmental goals may come at the expense of the populations impacted by such policy (Coad et al., 2008; Adams et al., 2004).

The dearth of quality evidence on the impacts of protected areas fuels a general debate regarding the relationship between areas protected by environmental law and the socioeconomic outcomes in surrounding areas. Conservationists see the establishment of protected areas as essential to global environmental stability, whereas poverty advocates argue that, while the benefits from protecting these areas are paid to all, the costs are borne only by those proximal to the areas (Coad et al. 2008; Wilkie et al., 2006; Adams et al., 2004). This argument concerns the land-use laws associated with protected areas that restrict economic development by preventing forms of profitable activities such as the exploitation of natural resources and agricultural cultivation (Coad et al., 2008; Fleck et al. 2006).

There have been few empirical studies with the proper data and methodologies to accurately estimate the socioeconomic impacts of protected areas on local economies, especially in developing nations (exceptions include: Ferraro and Hanauer (2011); Ferraro et al. (2011); Andam et al. (2010); Sims (2010); Robalino and Villalobos-Fiatt (2010)). Most studies have either been ex ante

estimates of future costs and benefits, or ex post studies of observed states of welfare Andam et al. 2010; Wilkie et al., 2006). The ability to empirically measure the socioeconomic impacts of protected areas is complicated by the non-random nature in which areas are assigned to protection. The presence of such selection issues necessitates the use of sophisticated research design and 
methodologies, absent most previous studies. Further confounding the process is the fact that most developing nations do not have sufficiently rich data sets with which to measure pre- and post-treatment poverty outcomes ${ }^{1}$

Bolivia is an apt setting for evaluating the impacts of protected areas on poverty in surrounding communities. Bolivia is one of the most biodiverse countries in the world 2 Yet despite having a wealth of natural resources, Bolivia is one of the poorest countries in Latin America, with poverty levels upwards of $60 \%$ (Canavire-Bacarreza and Mariscal, 2010). Bolivia also has an extensive protected area network that was made effective by an identifiable restructuring of the existing system in 1992, followed by a surge in proliferation of new protected areas throughout the 90s. Moreover, Bolivia has rich biophysical and socioeconomic data that predate the effective establishment of protected areas.

Using rich biophysical and socioeconomic data, and quasi-experimental methods, we ask, "what would poverty outcomes in Bolivian communities affected by protected areas have been had protected areas not been established?" We find no evidence that communities affected by protected areas established between 1992 and 2000 fared any worse, between 1992 and 2001, than similar communities that remained unaffected by protected areas. In fact, all of our point estimates indicate that protected communities had differentially greater levels of poverty reduction. We find that these results are robust to a number of econometric specifications, sensitivity analyses, spillover analyses and placebo studies. Our results are concordant with findings of poverty alleviation due to the establishment of protected areas in Costa Rica (Andam et al. 2010) and Thailand Andam et al. 2010; Sims, 2010). However, unlike previous studies (Andam et al., 2010; Sims, 2010) our results indicate that naïve (uncontrolled) comparisons of protected and unprotected communities leads to an overestimation of the poverty alleviation associated with the establishment of protected areas. Accordingly, our results underscore the fact that protected area impacts are likely not gener-

\footnotetext{
${ }^{1}$ See Ferraro (2008) for a discussion on the components of a quality socioeconomic impact evaluation which include: 1) An appropriate measure of welfare; 2) observations on outcomes and pertinent covariates for both pre- and posttreatment; 3) relevant indicators for both treatment and control units, and; 4) observations of pretreatment covariates that affect both selection into treatment and socioeconomic outcomes.

${ }^{2}$ Bolivia is one of the 15 most biologically diverse countries in the world. It is recognized as one of the 11 nations with the greatest diversity of flora (about 20 thousand species) and one of the top 10 most abundant in terms of birds (1,400 species) and mammals (356 species). Information provided by the Protected Areas National Service of Bolivia SERNAP (2009). Moreover, according to an UNESCO report, Bolivia has the largest water reserves in Latin America and ranks $6^{\text {th }}$ in the world in terms of tropical moist forest resources (the third in the continent after Brazil and Mexico).
} 
alizable and, therefore, the importance of country-level protected area impact evaluations. To that end, our results add to the scientific body of knowledge on the socioeconomic impacts of protected areas in developing countries, which is exceedingly sparse.

\subsection{Background}

\subsubsection{Protected areas in Bolivia}

The evolution of the establishment and enforcement of protected areas in Bolivia is complex but can be defined, coarsely, by two periods: pre- and post-1992. A non-trivial amount of Bolivia's area was designated for protection between the late 30's and early 90's ${ }^{3}$ However, the criteria for establishing these areas were not uniform, or systematic. Most were established with little technical background and absent the participation of local actors (SERNAP, 2007). Furthermore, there was a lack of recognition and requisite enforcement within these areas, a phenomenon commonly referred to as, "paper parks" (e.g., Bruner et al. (2001)).

The progression of the theme of conservation and the consequent international commitments undertaken by countries in the early 90's, after the Rio Conference, led to the development of policy and institutional foundations related to the then new paradigm of sustainable development and environmental care. Thus, under the Environment Law (Law 1333), the National System of Protected Areas in Bolivia (SNAP) was created in 1992, defined as natural and cultural heritage of the State and public and social interest.

The Law 1333, defines protected areas in Bolivia as "natural areas with or without human intervention, declared under state protection by law, in order to protect and preserve the flora and fauna, genetic resources, natural ecosystems, watersheds and values of scientific, aesthetic, historical, economic and social interest, in order to conserve and protect natural and cultural heritage of the country." 4

The consequence of Bolivia's history of protection and Law 1333 is that, even for areas desig-

\footnotetext{
${ }^{3}$ The 10 protected areas that were established prior to the 1990 's cover $5,917,638$ ha which is approximately $1 / 3$ of the total protected area.

${ }^{4}$ One of the most important characteristics of Bolivia's protected areas is their compatibility with the existence of traditional indigenous people (Environment Law 1333, Section 60-65). Since its initiation in 1992, the National System of Protected Areas in Bolivia has been designed with a participatory approach, recognizing that the areas are occupied and are ancestral territories of indigenous populations. Therefore, the participation of local people is a fundamental in the main aspect of the system.
} 
nated prior to 1992, the effective establishment date of Bolivia's protected area system was 1992 (and thereafter). The identification of this administrative recognition and enforcement allows us to use 1992 as a baseline, pre-treatment year, after which the intervention impact of protected areas can be measured.

\subsubsection{Related literature}

There have been only a handful of studies on the socioeconomic impacts of protected areas that properly control for their non-random establishment. Further, there is no formal literature regarding the impacts of Bolivia's protected area network on socioeconomic outcomes. The closest study to this kind for Bolivia (Yáñez, 2006) examines the potential effects of three protected areas on poverty in Bolivia. Based on household surveys carried out near these protected areas, the author finds a small positive effect of protected areas on poverty. Nevertheless, this study not only has a small sample of protected areas, but also presents some methodological drawbacks such as selection bias and sample selection.

The most comparable study to ours is a quasi-experimental analysis of protected areas in Costa Rica Andam et al. 2010). The authors designate census tracts (segmentos) with 10\% or more of their areas protected, as treated. They then use matching techniques to construct a counterfactual group that is similar along pretreatment dimensions to the treated census tracts. The authors' calculation of average treatment effect on the treated (ATT) provides evidence that census tracts with protected areas that were established prior to 1980 had differentially greater levels of poverty reduction between 1973 and 2000 than comparable unprotected census tracts.

In a similar study Sims (2010) uses a continuous measure of the percent of land area protected within Thailand sub-districts to measure the marginal effect of protected areas (IUCN category I \& II) on a poverty headcount ratio. The author compiles an extensive set of pre- and post-treatment biophysical covariates. However, the outcome variable is only available for the contemporaneous period, therefore, the baseline levels of poverty are unknown. The results of the study show that when baseline geographic and development variables are controlled for, sub-districts with more protected area displayed lower poverty levels than comparison districts.

Robalino and Villalobos-Fiatt (2010) explore how national parks affect local wages in Costa Rica and how these effects vary within different areas of a park and among different social groups. They 
use highly disaggregated geographic references, and find that parks' effects on wages vary according to economic activity and proximity to the entrance of the park. Workers close to entrances receive higher wages and are employed in higher-paid, non-agricultural activities.

Several studies from the United States have shown no effect of protected areas on economic outcomes at the county level. In two studies, (Lewis et al., 2002, 2003) use a simultaneous equations framework to examine the county level effects of protected areas (publicly owned land designated for preservation and multiple use) in the Northern Forest Region of the United States on migration, on employment and wage composition. A broader study by (Duffy-Deno, 1998) uses a cross-section of intermountain western counties of the United States to determine the effect of protected areas (Wilderness, Forest Service and BLM land) on population and employment densities. The author finds no significant effect on either outcome of interest. However, all of these studies suffer from the lack of a true baseline, given that all of the protected areas were designated decades prior to the first census observations.

\section{Data and Methods}

\section{$2.1 \quad$ Data}

We employ three categories of spatial and demographic data in this study: (1) temporally distinct boundary mappings of terrestrial protected areas, (2) boundary mappings of municipalities for the 1992 and 2001 censuses and the underlying demography, and; (3) key biophysical characteristics believed to jointly affect the establishment of protected areas and poverty.

The 1992 and 2001 census data were obtained from the Bolivian National Statistical Office (INE). The census provides information that allows us to estimate socioeconomic indicators at municipal level, such as structural poverty measures, education, employment, housing and health. Information regarding Bolivia's protected areas and their boundaries was obtained from Servicio Nacional de Areas Protegidas (SERNAP) and the World Database on Protected Areas (WDPA). Further geographic data (e.g., road networks, digital elevation models, cities, forest cover, etc.) were obtained from NASA, Conservation International and Bolivian forest regulation office (Superintendencia Forestal). 


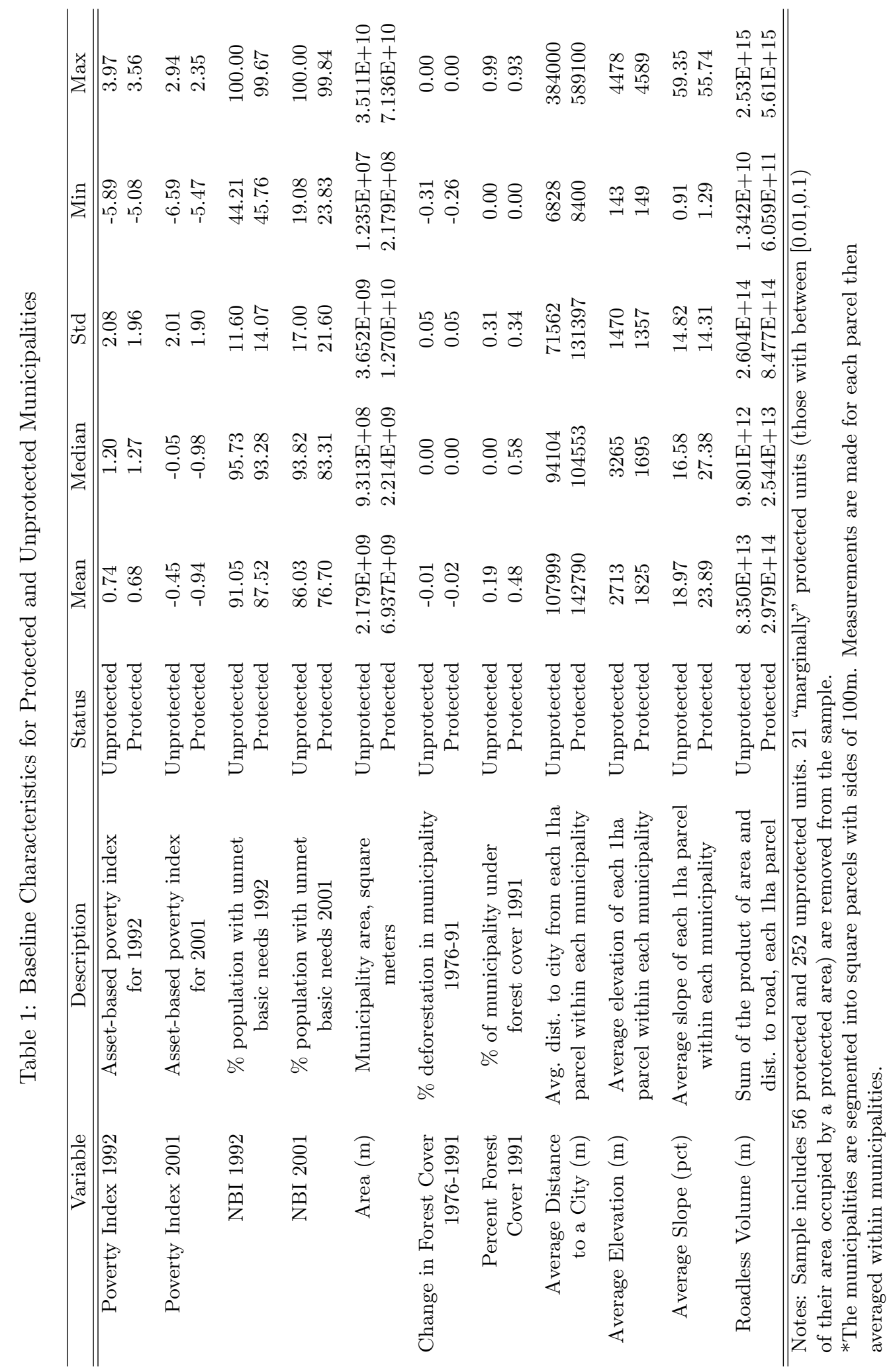




\subsubsection{Unit of analysis}

The unit of analysis for our study is the municipality. The municipality is the penultimate political boundary in terms of disaggregation, second to the comunidad. Bolivia comprises 327 municipalities with an average area of 325,083 ha (about the size of Rhode Island; range: 28,928 - 1,298,121 ha). The maps in Figures 1 and 2 show that the municipalities in the mountainous and altiplano regions (southwest) tend to be smaller than those in the lowlands (east northeast; see Figure 3 for the topography of Bolivia).

\subsubsection{Protected areas and treatment assignment}

Bolivia has 23 protected areas that cover a total area of 17,131,507.48 ha or $\sim 16$ percent of Bolivia's terrestrial area (GIS calculations). The average size of a protected area is 475,875 ha (range: 221 - 2,919,143 ha). To determine the socioeconomic impacts of protected areas we must identify the municipalities that are spatially influenced by protected areas. We use GIS to determine the proportion (percentage) of each municipality that is occupied by a protected area established between 1992 and 2000. Of the 87 municipalities that intersect with one or more protected area, the average area designated as protected is 29.3\% (range: $0.00007-100 \%$ ). In order to assign municipalities a binary indicator of treatment we must establish a threshold (percentage), above which municipalities are considered protected. Our initial threshold is established at $10 \% 5 \mathrm{In}$ order to reduce potential bias to our estimates we need to ensure that we are not comparing protected municipalities with marginally protected municipalities (doing so would likely serve to weaken estimates of treatment effect). We, therefore, drop municipalities with percentage overlap along the interval $[0.1,10)$. According to our assignment rule, there are 56 municipalities that are considered protected. The percentage of overlap within these protected municipalities ranges from $10.26-100 \%($ mean $=43.9 \%$, median $=39.14 \%)$. We are left with 256 municipalities that are considered unprotected.

\footnotetext{
${ }^{5}$ We use the $10 \%$ threshold in accordance with previous studies (Andam et al. 2010, Ferraro and Hanauer, 2011, Ferraro et al. 2011). A $10 \%$ threshold was chosen because one the goals of set forth by $4^{\text {th }}$ World Congress on National Parks and Protected Areas was to protect $10 \%$ of the worlds ecosystems (Andam et al., 2010). We test the robustness of our results to this protection threshold by defining alternative thresholds at 5, 20, 30 and $50 \%$. We find that our results are robust to these alternative thresholds (see Appendix for full threshold results).
} 


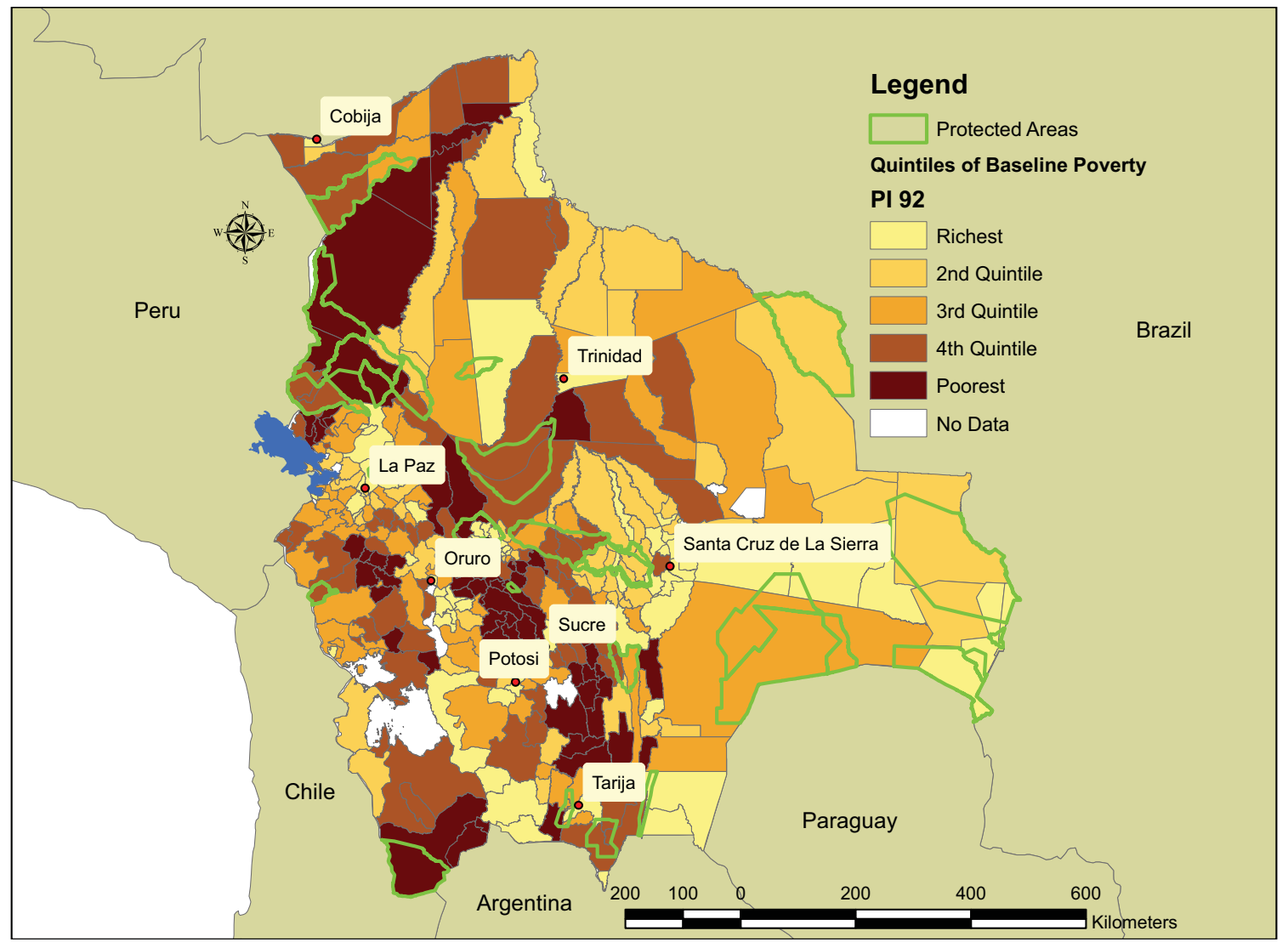

Figure 1: Map of protected areas, major cities and quintiles of poverty in 1992 according to poverty index. 


\subsubsection{Covariates of interest}

To isolate the causal effect of protected areas on poverty, we compile a set of observable covariates that jointly affect the establishment of protected areas and poverty outcomes (and assume that all unobservables do not exhibit joint influence). These covariates are used in our analyses to control for the observable differences between protected and unprotected municipalities, therefore, isolating the impact of protection.

Distance to major city. Cities tend to be the nodes of major markets, economic activity and opportunity. Protected areas are often located distant from major cities, where the opportunity cost of land is lower (Sims, 2010; Joppa and Pfaff, 2009). We calculate the average distance from each municipality to the nearest city (each municipality is broken into 1 ha parcels and the average euclidean distance from the set of parcels within each municipality to the nearest city is calculated using GIS). Cities included in the measurement are the state capitals: La Paz (and El Alto), Sucre, Cochabamba, Cobija, Trinidad, Oruro, Potosi, Tarija and Santa Cruz. Table 1 shows that protected municipalities are significantly farther from cities, on average, than unprotected municipalities. This is consistent with previous findings (e.g., Andam et al., 2010; Sims, 2010; Joppa and Pfaff, 2009).

Roadless volume. Access to roads increases access to markets and other resources (reducing transportation costs, etc.). In addition, roads serve as a good indicator of the level of infrastructure development and urbanization. Previous country-level studies have found that protected areas tend to be located in areas with sparse road networks (Andam et al., 2010, 2008). To control for baseline measures of these influences we calculate roadless volume (Watts et al., 2007). Roadless volume is an aggregation of the euclidean distance to a road for each land parcel within a municipality, adjusted for the size of the land parcel. Roadless volume is calculated by summing the product of the area of each land parcel (1 ha in this case) and the distance of that parcel to the nearest road (1992). Therefore, higher measurements of roadless volume indicate fewer road networks within a municipality. Table 1 shows that roadless volume is greater within protected municipalities, which is consistent with previous studies (e.g., Andam et al. 2010) ${ }^{6}$

Elevation and slope. Productivity of land, especially related to agricultural productivity,

\footnotetext{
${ }^{6}$ One may be concerned that disparate municipality areas across protected and unprotected units might confound the estimates of protected area impacts (e.g., may be correlated with urbanization or other unobservable). However, roadless volume is nearly perfectly correlated with the area of respective municipalities (Pearson correlation coefficient is 0.905), mitigating such concerns.
} 


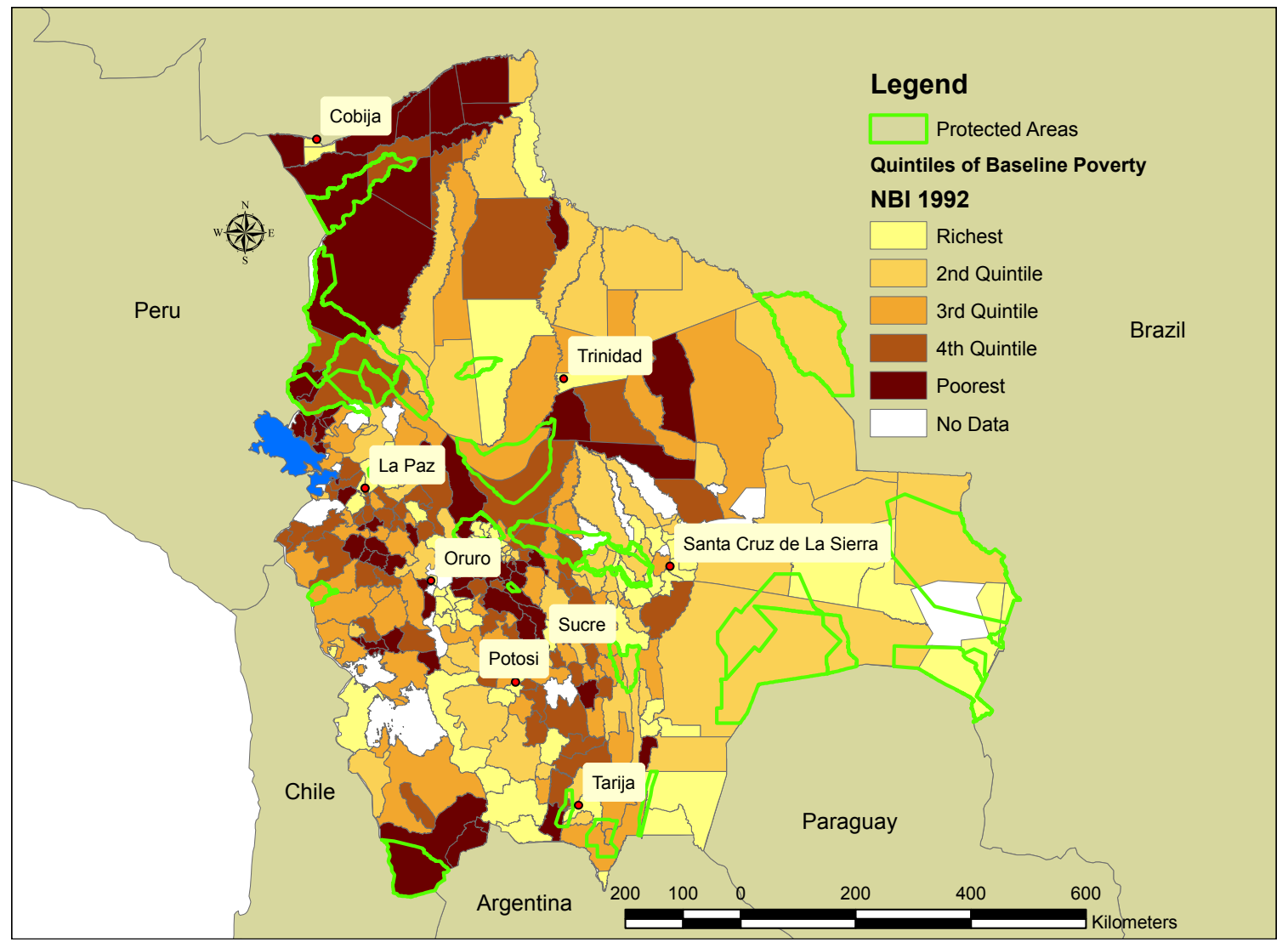

Figure 2: Map of protected areas, major cities and quintiles of poverty in 1992 according to NBI. 
plays a large role in economic development. Low slope, low elevation land tends to be more suitable for agriculture and general development (lower production, extraction and development costs). Previous studies, both globally (Joppa and Pfaff, 2009) and at the country-level Andam et al. 2010; Sims, 2010), have found that protected areas tend to be placed on land that is relatively steep and at high elevation. It is, therefore, important to control for the average slope and elevation of municipalities. Bolivia presents somewhat of a unique case, however. Bolivia is characterized by a dichotomous landscape in that the country is defined (in general) by the highlands and lowlands. Table 1 shows that the slope in protected municipalities is greater in unprotected municipalities (expected), however the average elevation is lower (on average) within these protected municipalities (unexpected).

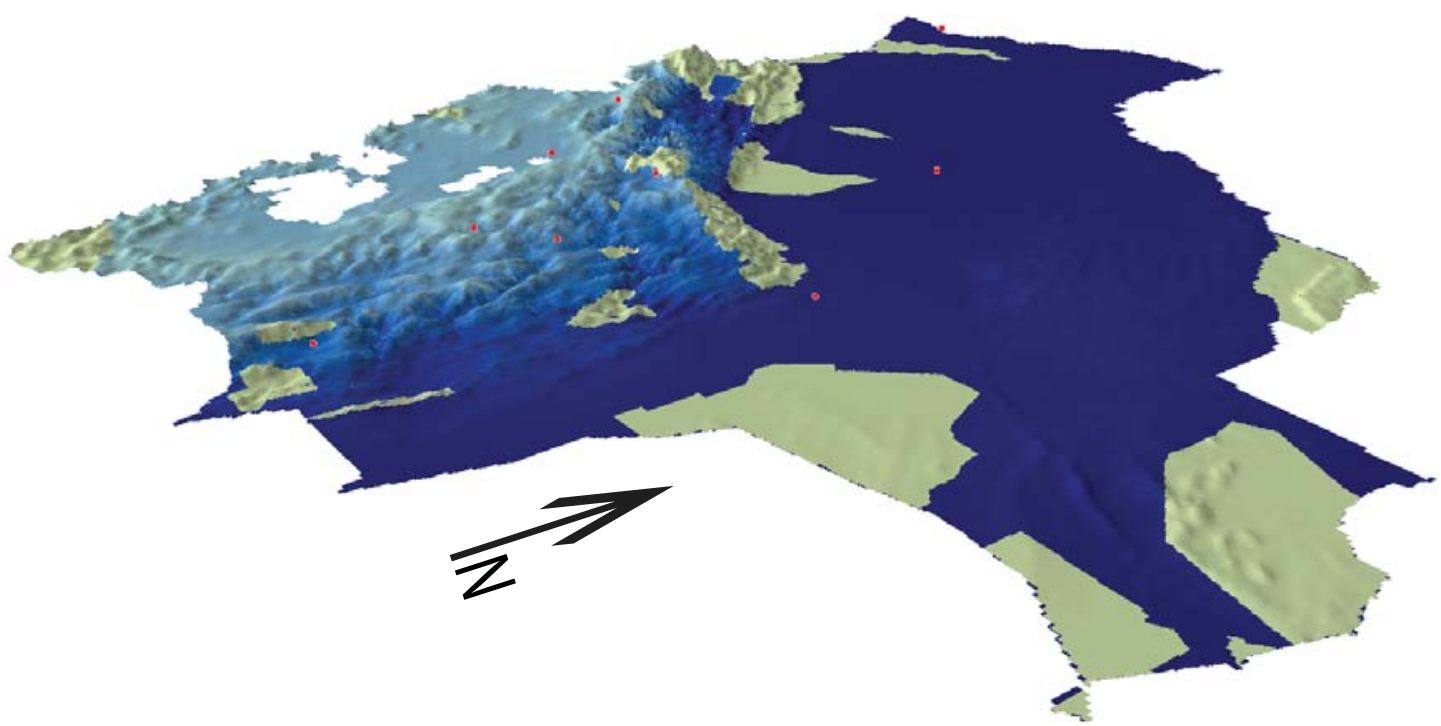

Figure 3: Digital elevation model of Bolivia, with protected areas draped (green). While a majority of the designated protected areas lie in relatively mountainous regions, there is a large area protected in the east that accounts for the relatively low average slope of protected municipalities. The red points represent the location of major cities listed in Figures 1 and 2.

Forest cover. Protected areas tend to be placed on forested lands (Andam et al., 2010; Sims, 2010). In addition, forests represent potential for economic opportunities (timber, fuelwood, etc.). We therefore calculate the percentage of each municipality covered by forest in 1991. Table 1 shows that protected municipalities contained significantly more forested areas at baseline. 


\subsubsection{Poverty}

In order to estimate the impact of protected areas on poverty, an outcome that objectively measures levels of socioeconomic welfare is necessary. In the absence of a universal metric such as income, we are tasked with developing metrics that adequately capture socioeconomic outcomes. We employ two measures of poverty in our analyses: (1) an asset based poverty index (PI), and, (2) Necesidades Basicas Insatisfechas (NBI). Both poverty indicators are measured during the 1992 and 2001 census years and serve two purposes. First, the PI and NBI in 2001 serve as the outcome of interest to measure differences in poverty between protected and unprotected municipalities. Second, the PI and NBI in 1992 serve as controls for baseline states of poverty. By ensuring that we compare protected and unprotected municipalities with similar baseline poverty characteristics, we improve the probability that these units share similar poverty trajectories prior to the establishment of protected areas.

Table 2: Eigenvectors from principal component analysis

\begin{tabular}{rr}
\hline Eigenvectors, Pooled & EigenV \\
\hline Variable & -0.02836 \\
Adult men in population* & 0.34984 \\
Households without bathroom* & 0.39719 \\
Households that use fuelwood for cooking* & 0.39399 \\
Households with dirt floors* & 0.33074 \\
Low-quality houses* & 0.46972 \\
Households without electricity* & 0.17906 \\
Illiterate population* & -0.06499 \\
Population employed with salary* & 0.00384 \\
Average persons per bedroom & 0.39091 \\
Households without access to public water* & 0.20994 \\
Households without sewer or septic* & -0.02452 \\
Average years of education & \\
\hline \hline Notes: Census data from 1992 and 2001 are pooled to measure \\
average influence of assets across time. \\
* Indicates that variable is measured as a percentage.
\end{tabular}

We use two separate measures of poverty to buttress the robustness of our analyses. Although the PI and NBI are both designed as measures of poverty, they capture different aspects that contribute to poverty:7

\footnotetext{
${ }^{7}$ Given that we do not have a more direct metric for poverty, such as income, we feel that it is important not to limit our analyses to a single proxy.
} 
Table 3: Mean Asset Values by Deciles of 1992 Poverty Index

\begin{tabular}{rcccccccccc}
\hline & \multicolumn{3}{c}{ Richer } & \multicolumn{4}{c}{ Deciles of PI 1992 } & \multicolumn{3}{c}{ Poorer } \\
\cline { 2 - 11 } Variable & 1 & 2 & 3 & 4 & 5 & 6 & 7 & 8 & 9 & 10 \\
\hline \hline pct.men.92 & 57.77 & 55.96 & 55.78 & 54.74 & 54.45 & 56.5 & 55.1 & 54.56 & 54.3 & 57.9 \\
pct.wo.bath.92 & 43.96 & 66.88 & 61.13 & 68.52 & 77.72 & 86.13 & 82.14 & 85.15 & 92.49 & 99.26 \\
pct.fuelwood.92 & 25.59 & 46.61 & 70.06 & 69.85 & 65.79 & 74.67 & 82.98 & 89.47 & 91.4 & 99.2 \\
pct.dirt.floor.92 & 28.77 & 49.74 & 63.72 & 72.77 & 76.89 & 79.72 & 80.52 & 81.61 & 92.19 & 91.7 \\
pct.low.qual.house.92 & 15.23 & 23.07 & 37.02 & 41.09 & 49.08 & 47.7 & 57.57 & 58.63 & 68.46 & 82.57 \\
pct.wo.elct.92 & 26.35 & 45.1 & 63.42 & 73.31 & 82.13 & 86.89 & 94.17 & 94.65 & 97.19 & 99.87 \\
illit.92 & 12.5 & 19.32 & 23.11 & 27.04 & 24.7 & 33.12 & 30.24 & 37.22 & 47.19 & 67.91 \\
emp.92 & 95.8 & 91.28 & 90.17 & 88.66 & 89.6 & 88.09 & 85.62 & 84.93 & 81.45 & 61.62 \\
avg.person.room.92 & 3.28 & 3.26 & 3.48 & 3.52 & 3.42 & 3.34 & 3.53 & 3.57 & 3.77 & 4.09 \\
pct.nowater.92 & 27.13 & 46.12 & 59.33 & 69.38 & 75.83 & 75.63 & 77.57 & 83.98 & 90.18 & 97.56 \\
pct.nosewer.92 & 65.05 & 87.19 & 90.97 & 93.19 & 96.16 & 96.98 & 97.34 & 98.5 & 99.03 & 99.87 \\
avg.edu.92 & 6.77 & 5.1 & 4.66 & 4.2 & 4.42 & 3.68 & 3.77 & 3.36 & 2.72 & 1.45 \\
\hline \hline
\end{tabular}

Poverty Index (PI) $8^{8}$ Our PI is an asset based poverty index founded on household responses to the 1992 and 2001 censuses. The index is constructed using a principal component analysis (PCA). The primary purpose of the PCA is to measure the influence of a vector of variables on a latent outcome, poverty. The relative influence of each component variable is measured by the eigenvectors (factor loading) calculated from the variance/covariance matrix underlying the component variables. The eigenvectors are combined with the relative municipal-level variation in assets to calculate a municipal-level PI.

Table 2 lists the variables used in the construction of the poverty index, and the eigenvectors associated with each asset 9 These eigenvectors (from the first component) account for over $60 \%$ of the variation in the asset variables and provide the factor scores $F_{j}$ for asset $j \in\{1,2, \ldots, J\}$ which indicate the weight and direction of the influence each asset $a_{j}$ exerts on the PI. These factor scores are combined with observed asset levels to formulate the PI for municipality $i \in\{1,2, \ldots, N\}$,

$$
P I_{i}=\sum_{1}^{J} F_{j}\left[\frac{a_{i j}-\bar{a}_{j}}{s_{j}}\right]
$$

where $a_{i j}$ is the observed level of asset $j$ in municipality $i, \bar{a}_{j}$ is the mean of asset $j$ across all municipalities, and $s_{j}$ is the standard deviation of asset $j$ across municipalities. The intuition underlying our PI is that there are a number of household assets and characteristics that explain

\footnotetext{
${ }^{8}$ A similar asset based poverty index was developed for Costa Rica (Andam et al., 2010, Cavatassi et al., 2004) and used by the Mexican government in the analyses of the PROGRESA program (cited by Cavatassi et al. (2004).

${ }^{9}$ Our analyses are designed to measure changes in poverty over time. To ensure that our poverty indexes are comparable across time we pool the asset data from the 1992 and 2001 census data similar to Cavatassi et al. (2004) (see also (Filmer and Pritchett, 2001)). By pooling the data for the PCA we estimate the mean influence of each asset across time, allowing the variation in assets between time periods to drive the estimated changes in poverty.
} 
variation in unobserved poverty outcomes. By understanding of how these assets co-vary (and by how much), we can infer, from the composition of these assets across municipalities, how relative poverty levels vary across municipalities.

We confirm the validity of our PI both internally and externally. The factor scores from the eigenvectors in Table 2 provide evidence that our PI is internally coherent. A positive factor score indicates that the asset variable contributes (adds) to poverty, and vice versa. The factor score of each asset variable carries the expected sign 10 We provide further evidence of the internal validity of our PI in Table 3, in which we list the mean values of each asset within the deciles of the 1992 PI. The trends in asset levels as the PI increases (increasing deciles) are similar to what we would expect to see as wealth decreases, indicating that the PI is likely capturing poverty. As an external (to the PI) measure of our poverty index's validity we measure the correlation between the PI and NBI. Although the PI and NBI capture different aspects of poverty, the two measures should be correlated. We find that this is the case, for instance, the correlation between NBI and PI in 2001 is over 0.8811

NBI. The NBI measures the percentage of the population within a municipality with unsatisfied basic human needs. It captures poverty by measuring the goods or services that a household possesses that are associated with well-being and then comparing these municipality-level values to a norm (or ideal). The Bolivian NBI was estimated by the INE in coordination with UDAPE. It comprises a set of factors such as housing, basic services, education and health ${ }^{12}$ The housing component aims to isolate the household environment, in terms of providing protection from the outdoors and other external factors such as animals and insects that transmit diseases. It also includes living spaces inside the household in order to consider social environment, privacy and comfort. The basic services component considers basic sanitation in terms of the need for good quality water for food and hygiene, and the availability of health services that allow privacy, sanitation and hygiene. In addition, NBI considers energy availability and cooking sources. The education portion includes the years of schooling, school attainment and literacy. Finally, the health com-

\footnotetext{
${ }^{10}$ According to the manner in which the poverty index was constructed, poverty is decreasing in the negative orthant.

${ }^{11}$ This correlation can be observed spatially in the maps in Figures 1 and 2 .

${ }^{12}$ The health component of the Bolivian NBI is not fully comparable between censuses as the questions have changed. However the change has been accepted and approved by the Bolivian government. The full methodology can be found at http://www.ine.gob.bo/pdf/Metodologias2004/NBI.doc
} 
ponent relates to the capabilities of people, and good health that allows the proper development within the social environment.

The individual household components are compared to a norm which is used to determine if the household's basic needs are met. The compilation of each equally weighted component allows for the identification of the poverty condition of each household 13 Accordingly, a higher measure of the NBI indicates greater poverty within the associated municipality.

\subsubsection{Baseline covariate distributions}

Previous studies at the global and country level have found significant differences in the biophysical Andam et al. 2010, Sims, 2010; Joppa and Pfaff, 2009, Pfaff et al., 2009) and socioeconomic Andam et al., 2010 characteristics underlying protected and unprotected areas. The differences underscore the non-random nature in which protected areas are allocated. Globally it has been shown that protected areas tend to be located distant from cities (markets) and on agriculturally unsuitable land (high slope, high elevation), so-called "high and far" or "rocks and ice" bias (Joppa and Pfaff, 2009). In addition, a similar study in Costa Rica demonstrated that communities affected by protected areas had significantly higher levels of baseline poverty than unaffected communities (Andam et al., 2010).

Table 1 shows that Bolivia shares many of the characteristics associated with protected areas that are observed globally. The geographic characteristics associated with access to markets, infrastructure and urbanization differ significantly between protected and unprotected areas. The average distance to a major city, roadless volume and percent baseline forest cover are greater in protected municipalities, indicating that protected areas tend to be established in more rural areas. In addition, it can be seen that one of the primary indicators of agricultural suitability, slope, is greater (indicating lower suitability) in protected municipalities. However, contrary to global trends, we observe that the average elevation in protected municipalities is lower than in unprotected municipalities (see Figure 3). Most interesting is the fact that, according to both poverty

\footnotetext{
${ }^{13}$ The methods used to formulate the NBI present some limitations related to the weight of the components that are included in the index. All the factors included have the same weight, in addition, the method require some norms to which indicators are compared. These norms are, to some extent, arbitrary. Also, a household is considered poor if at least one of the NBI components are not satisfied. Moreover, NBI does not consider explicitly the demographic structure of the household and prioritizes the housing indicators. There is one final, practical, limitation: there are 13 municipalities (four of which are considered protected) for which NBI was not calculated in 1992.
} 
measures, baseline poverty is slightly lower in protected municipalities. This finding is contrary to findings from Costa Rica (Andam et al. 2010) and common wisdom.

\subsection{Methods}

The underlying differences in covariate values between protected and unprotected municipalities underscores the importance of controlling for such differences in the estimation of the impacts of protected areas. The selection issue that we must address is that protected areas are not established randomly across the landscape. Non-random allocation leads to the observed imbalance across these key covariates, that jointly determine selection into protection and socioeconomic outcomes (see Table 1), which may lead to biased estimates of the impacts of protected areas under naïve comparisons of protected and unprotected municipalities. To reduce the bias associated with our estimates of the socioeconomic impacts of protected areas, we use matching as our primary strategy to control for this confounding imbalance.

\subsubsection{Matching}

To measure the impact of protected areas on poverty in surrounding municipalities we use matching to estimate the average treatment effect on the treated (ATT). Estimation of the ATT is implied in our research question, "what would poverty outcomes in protected municipalities have been had they not been protected?" Answering such a question requires the estimation of a counterfactual, and because there are municipalities for which it is implausible to suppose the establishment of a protected area, the estimation of an ATT is most appropriate 14

The key to matching as an identification strategy to estimate ATT is the balancing of covariate distributions across treatment arms (protected and unprotected) thus mimicking the identification strategy of a randomized experiment. This covariate balance is achieved in expectation through randomization. Covariate balance is implicit under randomization because each unit of the experimental sample has an equal probability (or more generally, a probability that is known to the experimenter) of being assigned to treatment or control. Therefore, treatment is assigned independent of potential outcomes $Y(1)$ and $Y(0)$ under treatment $(T=1)$ and control $(T=0)$,

\footnotetext{
${ }^{14}$ Estimation of average treatment effects (ATE), for instance, entails the estimation of an additional counterfactual: outcomes for all unprotected units had they been protected. We argue that it is implausible for many of Bolivia's municipalities to have been protected and, therefore, the estimation of ATT is more appropriate that ATE.
} 
respectively. In the absence of a treatment, one would expect similar average outcomes from both groups. Similarly, if both groups were to receive (the same) treatment, one would expect similar average outcomes from both groups. In the statistics, epidemiology and social science literature this assumption is termed ignorability of treatment, independence of treatment or unconfoundedness. Stated formally,

$$
\begin{aligned}
& E[Y(1) \mid T=1)]=E[Y(1) \mid T=0)]=E[Y(1)] \\
& E[Y(0) \mid T=1)]=E[Y(0) \mid T=0)]=E[Y(0)] .
\end{aligned}
$$

In words, (2) simply states that average potential outcome for the treatment group under treatment, $E[Y(1) \mid T=1)]$, is equal to the average potential outcome of the control group had they been treated, $E[Y(1) \mid T=0)]$. Similarly, (3) states that the average potential outcome for the treated group had they not been treated, $E[Y(0) \mid T=1)]$, is equal to the average potential outcome of the control group in the absence of treatment, $E[Y(0) \mid T=0)]$. In (2) and (3), the terms $E[Y(1) \mid T=0)]$ and $E[Y(0) \mid T=1)]$ are termed counterfactual outcomes. The fundamental problem for causal inference (Holland, 1986) is the fact that counterfactual outcomes are not observed. However, with treatment assigned at random (and thus independent of potential outcomes), the average outcome for control units can act as the counterfactual for treatment units, and vice versa.

Protected areas in Bolivia were not established randomly. Matching seeks to mimic the identification of randomization by balancing key covariates that jointly determine selection into treatment and outcomes. Balance, conditional on key covariates, leads to conditional ignorability or conditional independence. However, because our primary estimand of interest is the ATT we only need to estimate one counterfactual. Therefore, it is only necessary for us to invoke the conditional independence assumption (CIA) for (2). This more restrictive assumption can be stated formally as the analog to $(2)$,

$$
E[Y(0) \mid T=1, X]=E[Y(0) \mid T=0, X)]=E[Y(0) \mid X]
$$

Equation (4) states that, conditional on similar covariate distributions across treatment arms, the average outcomes for the matched control units, $E[Y(0) \mid X, T=0)]$, can be used as the coun- 
terfactual for treatment units. In other words, by ensuring that the distributions of key covariates are balanced across treatment and control groups, similar methods to those used in randomized experiments can be used to estimate ATT on matched datasets 15 By ensuring that units are comparable across treatment and control groups, we make the CIA, which is necessary for causal inference, more defensible (Angrist and Pischke, 2009).

\subsubsection{Primary estimator}

There are many matching metrics from which to choose. Our final specification is determined by the metric that provides the best balance across our covariates of interest ${ }^{16}$ We find that, given our relatively small sample size, genetic matching provides the best balance and, therefore, is most likely to satisfy the CIA. Genetic matching (Sekhon, 2007) conducts an algorithmic search across potential weighting matrices in order to optimize the weighting matrix to best satisfy covariate balance. We conduct a series of robustness checks on the estimates stemming from the genetic matching, including adding calipers, calculating the Rosenbaum bounds (Rosenbaum, 2002), and various regression based estimators (see the Robustness Section below).

Our primary genetic matching specification uses the single nearest neighbor (in terms of covariate distribution) to each treated unit to act as the counterfactual for each treated unit. We allow for replacement (which generally reduces bias but can increase the variance Imbens and Wooldridge, 2009 Dehejia and Wahba, 2002)) during matching, use a post-match regression bias-adjustment (Imbens and Wooldridge, 2009; Abadie and Imbens, 2006; Abadie et al., 2004), ${ }^{17}$ and calculate so-called Abadie and Imbens (2006) heteroskedasticity robust standard errors. Our matching specification seeks to find an unprotected municipality that is observably similar to each protected municipality, isolating the only remaining variation between treatment arms to be the establishment of protected areas, thereby allowing the unbiased estimation of ATT.

\footnotetext{
${ }^{15}$ Similarly, by additionally invoking CIA for equation (3) (i.e., $\left.E[Y(1) \mid T=1, X]=E[Y(1) \mid T=0, X)\right]=$ $E[Y(1) \mid X])$, average treatment effects can be measured.

${ }^{16}$ During the process of selecting a matching metric we tested the balancing properties of many different metrics (e.g., Mahalanobis, propensity score and inverse covariance). Outcomes and ATT estimates were omitted while inspecting balance across different specifications to prevent the estimates from potentially affecting the selection of a metric.

${ }^{17}$ Because our matched samples are relatively balanced, the post-match regression bias adjustment has relatively little effect on the point estimates.
} 


\section{Results}

\subsection{Primary Results}

Figure 4 and Table 4 present the results from our primary, and ancillary robustness, analyses (Tables 5 and 6 provide balancing results from our primary matching specifications). In this subsection we focus on the second column of the respective right, and left, hand bar charts and the respective row in Table 4, which present the ATT estimates stemming from the genetic matching algorithm.

For both our PI and NBI poverty indicators we find no evidence to suggest that the establishment of protected areas in Bolivia had deleterious effects on poverty. To the contrary, all of our point estimates indicate that protected areas were likely associated with poverty alleviation. In other words, after controlling for covariates that jointly influence the establishment of protected areas and poverty, we find that there was differentially greater poverty reduction between 1992 and 2001 in municipalities that had at least $10 \%$ of their area occupied by a protected area. The point estimates from the primary specification are statistically significant (at any standard level) when the PI is used as the outcome of interest, but is insignificant when NBI is used as the outcome of interest (though the point estimates are concordant with those of the PI).

An attractive feature of our matching-based estimator is its transparency in terms of allowing for the identification of mean poverty outcomes across treatment arms of the matched sample, which represent the components of the ATT. Table 4highlights the underlying difference between the naïve and genetic matching estimates, which stem from the formulation of the counterfactual sample. When the counterfactual comprises all unprotected municipalities other than those marginally protected, the counterfactual poverty outcome (the poverty level that would have been observed in protected municipalities, had they not been protected) is -0.451 (85.61) according to the PI (NBI). Under our genetic matching specification we are left with 56 and 53 counterfactual unprotected municipalities for the PI and NBI analyses, respectively (41 and 38 of which are unique in the respective analyses). The associated counterfactual outcome estimates are more similar to the treated sample (-0.805 for the PI and 84.16 for $\mathrm{NBI})$, resulting in a more modest estimate of the poverty reduction associated with the establishment of protected areas for both poverty metrics.

Our results are concordant with previous studies from Costa Rica (Andam et al., 2010) and Thailand (Andam et al., 2010; Sims, 2010): protected areas are associated with poverty reduction. 
However, our results differ fundamentally from these previous studies. Andam et al. (2010) and Sims (2010) find that naïve estimates of protected area impacts indicate that protected areas exacerbated poverty. When key covariates are controlled for, however, their results reverse. In contrast, our results indicate that a failure to control for key covariates leads to the over estimation of the impacts of protected areas on poverty reduction.

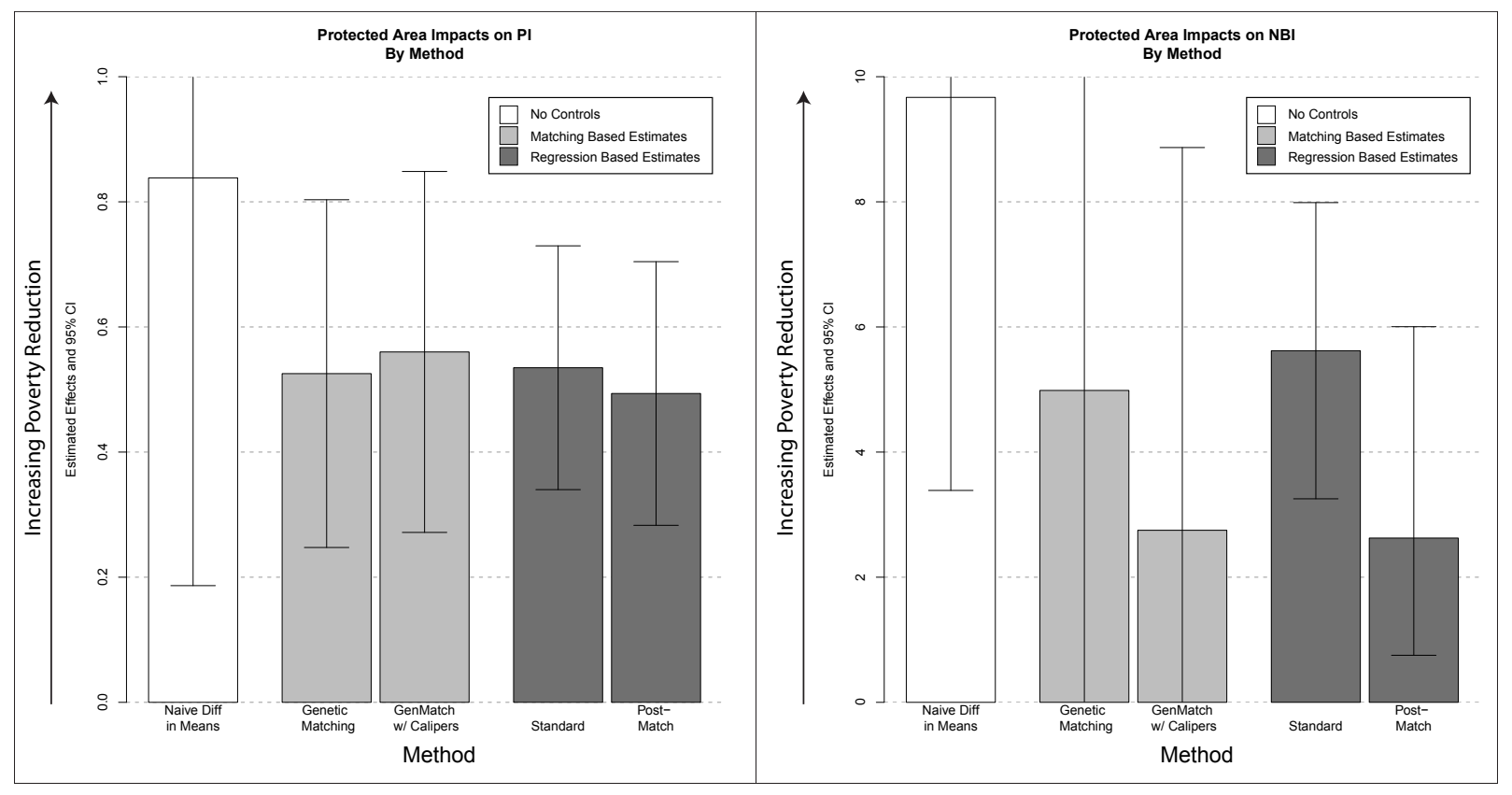

Figure 4: Primary estimates of the impacts of protected areas on poverty in Bolivia. The left hand (right hand) group of bars represent the impact according to poverty index (NBI) across a number of econometric specifications. The results from the primary genetic matching specification described in Methods can be found in the second bar of the respective bar groups. The whiskers represent the $95 \%$ confidence interval for the corresponding point estimates underlying each bar.

\subsection{Robustness}

We test the robustness of our primary estimates in several ways. First, we test the sensitivity of our matching estimator to unobserved heterogeneity between protected and unprotected units. The purpose is to identify by how much the groups would have to differ (unobservably) in order to nullify our results of statistically significant poverty reduction. Second, we test the robustness of our matching specifications by comparing our primary specification to a number of matching- and regression-based econometric specifications. 


\subsubsection{Internal robustness of matching specification}

In any observational study it must be acknowledged that the ability to eliminate bias associated with non-random selection is limited by one's understanding of the underlying selection process (Meyer, 1995), moreover, from a practical standpoint, by the pertinent characteristics of selection that one can actually observe and obtain. If the selection process and outcomes are systematically determined only by observable characteristics (for which one controls) then a treatment effect estimate derived from a matching algorithm that provides balance will be unbiased and consistent. However, if there are unobservable characteristics that are uncorrelated with observable characteristics for which we control but also contribute to determining selection and outcomes, then treatment effect estimates, even for a well balanced matched sample, may be biased. We believe our data are rich enough to provide sufficient covariates with which to control, therefore mitigating unobserved heterogeneity. However, we test the sensitivity of our ATT estimates to unobserved heterogeneity/bias using Rosenbaum bounds (Rosenbaum, 2002).

The Rosenbaum bounds sensitivity analysis measures the amount of unobserved heterogeneity necessary to undermine the statistical results from our matching process. If a great (small) amount of unobserved heterogeneity is necessary to weaken the significance of our results then the results are relatively robust (sensitive) ${ }^{18}$ Table 7 indicates the level of unobserved heterogeneity (unaccounted for in our matching process) that would be necessary to nullify our findings of statistically significant poverty reduction according to the PI. Our results are robust (at the $5 \%$ level) to unobserved heterogeneity that affects the odds of selection into protection by a factor of 2.3. In other words, these results are highly robust to potential unobserved bias.

\subsubsection{Robustness of matching specification to alternative econometric specifications}

To ensure that our results are not sensitive to the choice of econometric specification, we conduct a series of ancillary matching- and regression-based analyses. The results of these analyses can be found in Figure 4 and Table 4.

Genetic matching with calipers. In our primary econometric specification we use one-toone nearest neighbor matching based on the genetic matching algorithm. Although we achieve a

\footnotetext{
${ }^{18}$ See Appendix for full details on Rosenbaum bounds.
} 
high level of balance across treatment arms, there are invariably a number of treated units that do not obtain a well-matched control/counterfactual unit. To ensure that a few poorly matched units are not biasing or driving the results, we impose calipers, equal to one standard deviation, on our primary matching specification. In other words, we use the identical genetic weighting matrix, however, we remove from the sample any matched pair that differ by more than one standard deviation across covariate values 19

Table 4: Results from Primary and Ancillary Analyses

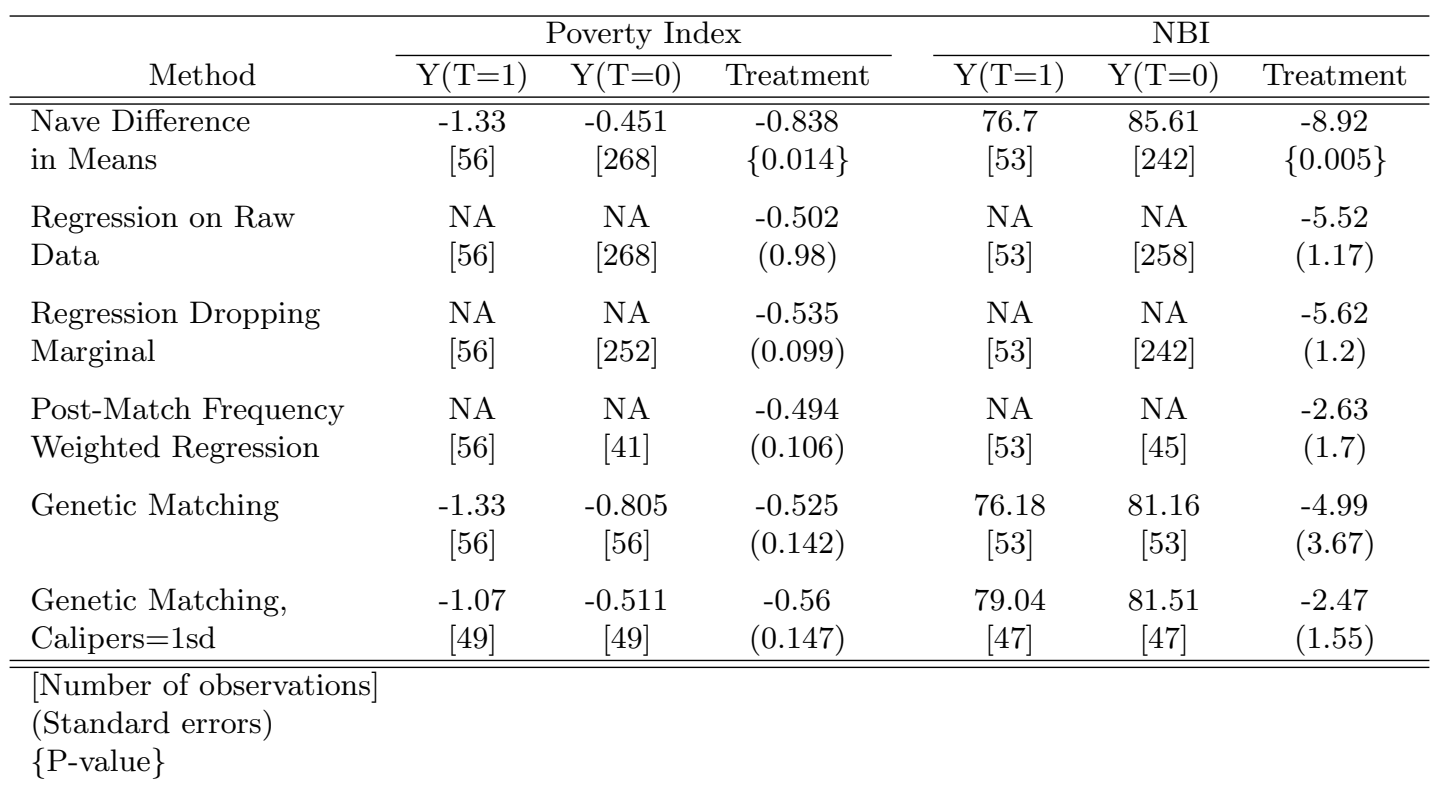

Figure 4 and Table 4 show that the results for the PI are relatively robust to the introduction of calipers, i.e., there is only a marginal absolute increase in the point estimate of ATT. Seven protected municipalities are dropped from the analysis, resulting in a bilateral increase in PI outcomes across matched protected and unprotected municipalities (from -1.33 to -1.07 and -0.805 to -0.511 , respectively). The variance of the resulting ATT changes little and the point estimate is significant at any conventional level.

Results for NBI are not as robust. Six protected municipalities are dropped from the sample resulting in an absolute reduction in the ATT from -4.99 to -2.47. Table 4 indicates that this change is due to opposite movements in average poverty across the protected and unprotected samples.

\footnotetext{
${ }^{19}$ The variance is measured according to the scalar value assigned to each unit after taking the product of the covariate values of each unit and the genetic weighting matrix. This scalar, like a propensity score, mitigates the so-called curse of dimensionality associated with multivariate matching.
} 
Average NBI in protected municipalities increased from 76.18 to 79.04 while average NBI in unprotected municipalities decreased from 84.16 to 81.51. Although the variance in ATT decreases after calipers are imposed, the resulting ATT estimate remains insignificant at conventional levels.

Regression-based specifications. We run several regression-based econometric specifications to ensure that our results are not driven by the use of a matching-based estimator. The results of these specifications are found in Table 4 (see Appendix Table A 15 for full regression results) and we highlight these specifications in last two columns of each bar group of Figure 4. Although there is slightly greater heterogeneity in the specifications for which NBI is the outcome, the central results from these specifications are that: (1) protected areas are associated with significant poverty reductions according to both the PI and NBI, and; (2) the results do not differ significantly from the primary matching-based estimates.

Table 5: Balance Results for Primary GenMatch Specification- PI

\begin{tabular}{|c|c|c|c|c|c|c|c|}
\hline Covariate & Status & $\begin{array}{l}\text { Mean } \\
\text { Prot. }\end{array}$ & $\begin{array}{c}\text { Mean } \\
\text { Unprot. }\end{array}$ & $\begin{array}{c}\text { Diff. } \\
\text { in Means }\end{array}$ & $\begin{array}{l}\text { Norm. } \\
\text { Diff. }^{\dagger}\end{array}$ & $\begin{array}{c}\text { Mean eQQ } \\
\text { Diff. }{ }^{\ddagger}\end{array}$ & $\begin{array}{l}\text { \%Improve } \\
\text { Mean Diff. }\end{array}$ \\
\hline Poverty Index & Unmatched & 0.267 & 0.744 & -0.477 & 0.141 & 0.436 & \\
\hline 1992 & Matched & 0.267 & 0.319 & -0.052 & 0.015 & 0.164 & $89.12 \%$ \\
\hline \multirow[t]{2}{*}{ \% Forest 1991} & Unmatched & 0.485 & 0.194 & 0.291 & 0.476 & 0.292 & \\
\hline & Matched & 0.485 & 0.466 & 0.019 & 0.029 & 0.037 & $93.40 \%$ \\
\hline Distance to & Unmatched & 142800 & 108000 & 34790 & 0.173 & 35950 & \\
\hline Major City & Matched & 142800 & 136600 & 6151 & 0.029 & 32940 & $82.32 \%$ \\
\hline Average & Unmatched & 1825 & 2713 & -888 & 0.307 & 884 & \\
\hline Elevation & Matched & 1825 & 1794 & 30.94 & 0.011 & 118.9 & $96.52 \%$ \\
\hline \multirow[t]{2}{*}{ Average Slope } & Unmatched & 23.89 & 18.97 & 4.922 & 0.162 & 5.34 & \\
\hline & Matched & 23.89 & 23.89 & 0.004 & 0.000 & 1.628 & $99.92 \%$ \\
\hline Roadless & Unmatched & $2.98 \mathrm{E}+14$ & $8.35 \mathrm{E}+13$ & $2.14 \mathrm{E}+14$ & 0.194 & $1.96 \mathrm{E}+14$ & \\
\hline Volume 1992 & Matched & $2.98 \mathrm{E}+14$ & $2.53 \mathrm{E}+14$ & $4.53 \mathrm{E}+13$ & 0.030 & $1.27 \mathrm{E}+14$ & $78.89 \%$ \\
\hline
\end{tabular}

Bar columns 4 and 5 of each bar group in Figure 4 present the results of a standard regression (marginally protected units are dropped from the sample and all covariates are included as controls), and a post-match frequency weighted regression ${ }^{20}$ respectively.

Both the regression-based analyses for which the PI is the outcome of interest (bars 4 and 5 on

\footnotetext{
${ }^{20}$ The post-match frequency weight regression is conducted on the resulting matched sample from the primary genetic matching specification. To correct for potential overstatement in the precision of coefficient estimates (due to repeat matched unprotected observations) we drop all duplicate observations from the unprotected sample and then weight each unprotected unit by the number of times it was used as a match for a protected unit, to ensure unbiased coefficient estimates. This so-called "double robust" estimation strategy is promoted by Ho et al. (2007) because the second stage regression helps to eliminate any residual differences across treatment arms that remain after matching.
} 
Table 6: Balance Results for Primary GenMatch Specification- NBI

\begin{tabular}{|c|c|c|c|c|c|c|c|}
\hline Covariate & Status & $\begin{array}{l}\text { Mean } \\
\text { Prot. }\end{array}$ & $\begin{array}{c}\text { Mean } \\
\text { Unprot. }\end{array}$ & $\begin{array}{c}\text { Diff. } \\
\text { in Means }\end{array}$ & $\begin{array}{l}\text { Norm. } \\
\text { Diff. }^{\dagger}\end{array}$ & $\begin{array}{c}\text { Mean eQQ } \\
\text { Diff. }^{\ddagger} \\
\end{array}$ & $\begin{array}{l}\text { \%Improve } \\
\text { Mean Diff. }\end{array}$ \\
\hline \multirow[t]{2}{*}{ "NBI 1992} & Unmatched & 87.52 & 991.05 & -3.527 & 0.078 & 3.15 & \\
\hline & Matched & 87.52 & 87.56 & -0.044 & 0.001 & 0.97 & $98.74 \%$ \\
\hline \multirow[t]{2}{*}{ \% Forest 1991} & Unmatched & 0.464 & 0.187 & 0.277 & 0.453 & 0.277 & \\
\hline & Matched & 0.464 & 0.459 & 0.005 & 0.007 & 0.03 & $98.22 \%$ \\
\hline \multirow{2}{*}{$\begin{array}{l}\text { Distance to } \\
\text { Major City }\end{array}$} & Unmatched & 136400 & 108600 & 27790 & 0.140 & 29580 & \\
\hline & Matched & 136400 & 132600 & 3730 & 0.017 & 25160 & $86.58 \%$ \\
\hline Average & Unmatched & 1888 & 2751 & -863.1 & 0.299 & 862.8 & \\
\hline Elevation & Matched & 1888 & 1884 & 4.489 & 0.002 & 106.7 & $99.48 \%$ \\
\hline \multirow[t]{2}{*}{ Average Slope } & Unmatched & 24.01 & 19.45 & 4.555 & 0.149 & 5.055 & \\
\hline & Matched & 24.01 & 23.67 & 0.334 & 0.010 & 3.979 & $92.66 \%$ \\
\hline Roadless & Unmatched & $3.06 \mathrm{E}+14$ & $8.53 \mathrm{E}+13$ & $2.20 \mathrm{E}+14$ & 0.195 & $1.99 \mathrm{E}+14$ & \\
\hline Volume 1992 & Matched & $3.06 \mathrm{E}+14$ & $2.58 \mathrm{E}+14$ & $4.80 \mathrm{E}+13$ & 0.033 & $1.06 \mathrm{E}+14$ & $78.22 \%$ \\
\hline
\end{tabular}

the left hand side of Figure 44 return estimates that are strikingly similar to one another, and to the primary matching specification. The confidence intervals are slightly tighter than those from the matching based estimators (expected given the efficiency properties of OLS and the fact that the standard specification contains a larger sample of unprotected units). There is more heterogeneity in the impact estimates in which NBI is the outcome of interest. However, one of the more interesting results from the NBI regression specifications is that, although the estimated impacts of protected areas on poverty do not differ significantly from the primary matching specification, the impacts of protected areas on NBI are all significantly different from zero.

\subsection{Results Summary}

The central finding in our results is that it does not appear as if Bolivia's protected areas that were established between 1992 and 2000 had any negative effect on poverty in surrounding communities between 1992 and 2001. Rather, our results indicate that protected areas were likely associated with reductions in poverty. Though these results are relatively robust across specifications, a couple of questions linger.

\subsubsection{Effect Size of Impacts}

To measure poverty, and changes therein, we use two metrics that are neither directly comparable to one another nor standard measures (e.g., income). It is, therefore, difficult to interpreter 
whether or not the estimated socioeconomic impacts that we report are consistent across metrics, or economically interesting in terms of magnitude. We calculate the effect size (Cohen, 1988) for each of our primary impact estimates to overcome the non-comparability of our poverty metrics.

To calculate the effect size of our ATT estimates, we divide the respective estimates by the standard deviation of the matched unprotected units from the respective analyses. The effect size is, therefore, a standardized measure of by how much the distribution of the treatment group differs from that of the control group. The effect size estimates from our primary PI and NBI analyses are both -0.25 . This can be interpreted as follows: protected municipalities had, on average, 0.25 standard deviations lower PI and NBI than the associated matched controls ${ }^{21}$ According to Cohen (1988) this is a relatively small effect size; non-trivial, however.

Another benefit of calculating the effect size is that it allows us to draw comparison between our results and those of similar studies. Andam et al. (2010) make effect size calculations for there estimates of the poverty alleviating impacts of protected areas in Costa Rica and Thailand. There estimates fall on either side of ours at -0.2 and -0.43 for Costa Rica and Thailand, respectively.

\subsubsection{PI or NBI?}

Although the point estimates in all the primary and ancillary analyses indicate poverty reductions associated with protected areas, the results from analyses in which the PI is the outcome of interest are more consistent, and remain statistically significant. This begs the question, in which poverty measure we should place more stock? From a policy standpoint we argue that it matters little. There is no evidence that protected areas exacerbated poverty, by any measure. From a technical standpoint, however, we believe that the PI is more appropriate in our study.

The NBI has some technical and practical shortcomings, mentioned previously. First, the NBI weights all socioeconomic components equally, unlike the PI in which weights are determined empirically via the PCA. Second, the NBI measures the percentage of households that lie below a norm which is (somewhat) arbitrarily established. The PI, on the other hand, is based on deviations from municipality-level means (in either direction). Finally, and from a practical standpoint, analyses in which the NBI is used are limited by the fact that we do not have baseline NBI measurement for

\footnotetext{
${ }^{21}$ Another way to intemperate this effect size measurement would be that approximately $60 \%$ of the protected municipalities had lower PI and NBI measures than the matched controls.
} 
14 municipalities (four of which are considered protected).

\subsubsection{Why are the matching-based and regression-based estimates so similar?}

The goals of matching and regression in causal analysis are the same: achieve plausible conditional independence of the treatment. However, the two methods go about doing so in different manners. Regression isolates the causal effect of a treatment by imposing a functional relationship between treatment, covariates and outcome. Regression then isolates the causal effect of treatment by partialing out the effects of the covariates of interest. Instead of controlling for the differences across treatment arms via the imposition of a functional form, matching uses a weighting scheme ${ }^{22}$ to create balance in expectation across the covariates, thereby "controlling" for their influence.

Typically in an analysis in which the ATT is the estimand of interest we would expect greater differences in matching- and regression-based results. The reason relates to the idea of propensity for treatment. In a study like ours, where there are control units that would never plausibly be treated, the overlap in propensity for treatment is generally sparse (or completely lacking) at the tails of the distributions (of propensity scores and the underlying covariates) between protected and unprotected units. This scenario can lead to bias in regression results because the coefficient estimates can be heavily (and inappropriately) influenced by outlying control units (e.g., Ho et al. (2007)).

The reason that our results are so similar across matching- and regression-based estimates can be seen in Figure A2, We plot the distributions of propensity scores across treatment arms for preand post-matched samples. It can be seen that there is a high degree of overlap across the range of propensity scores even prior to matching (left panel of Figure A2). Therefore, it makes sense that the matching- and regression-based results are comparable because, even within the full sample, the regression results are not plagued by "out of sample" predictions.

\footnotetext{
${ }^{22}$ For example, with one-to-one matching without replacement, control units are excluded from the sample by receiving an effective weight of 0 whereas remaining units receive a weight of 1 .
} 
Table 7: Rosenbaum Upper Bound on P-Value at Given Levels of $\Gamma$ for Primary Matching Analysis- PI

\begin{tabular}{cc}
\hline & $\begin{array}{c}\text { Upper Bound } \\
\text { P-value }\end{array}$ \\
\hline \hline 1 & 0 \\
1.1 & 0.0001 \\
1.2 & 0.0003 \\
1.3 & 0.0007 \\
1.4 & 0.0015 \\
1.5 & 0.0029 \\
1.6 & 0.005 \\
1.7 & 0.0081 \\
1.8 & 0.0124 \\
1.9 & 0.018 \\
2 & 0.0253 \\
2.1 & 0.0342 \\
2.2 & 0.0448 \\
2.3 & 0.0572 \\
\hline
\end{tabular}

\section{Discussion}

Protected areas have played an increasingly important role in the global conservation of biodiversity and ecosystem services over the past several decades. However, there is little empirical evidence of the environmental impacts of protected areas and even less evidence of their socioeconomic impacts on surrounding communities. Given the high degree of overlap between remaining global biodiversity and poverty, it is of paramount importance to understand how the establishment of protected areas impacts poverty.

We use rich biophysical and socioeconomic data, and a myriad of econometric specifications to estimate the impact of protected areas established in Bolivia between 1992 and 2000 on poverty between 1992 and 2001. Contrary to the concerns of poverty advocates, that the land-use restrictions associated with protected areas impart economic hardship on surrounding communities, our results do not indicate that protected municipalities were adversely affected by the establishment of protected areas. In fact, we find evidence that municipalities with at least $10 \%$ of their areas occupied by a protected area had differentially greater poverty reduction than those unaffected by protected areas. We employ two separate measures of poverty in our analyses and find that the point estimates of poverty reduction are robust across our econometric specification.

Although our overarching results that Bolivia's protected areas were associated with poverty reduction are similar to previous studies from Costa Rica (Andam et al. 2010$)$ and Thailand (An- 
dam et al., 2010; Sims, 2010), our underlying results differ subtly, but significantly. In those studies the authors found that controlling for key observable covariates lead to fundamentally antithetical results compared to naïve estimates. Conversely, our results indicate that naïve estimates lead to an over estimation of the poverty reducing impacts of protected areas.

The implications of our results are twofold. First, our results add to a growing body of literature on the impacts of protected ares on poverty. More importantly our findings add support to this literature that environmental conservation policies do not necessarily run in opposition to development goals. On the contrary, our results indicate that environmental goals can be complementary to social poverty goals. Second, our results underscore the importance of country-level analyses of the socioeconomic impacts of protected areas. Protected areas in Bolivia exhibit many of the characteristics observed globally (i.e., located relatively distant from major cities, roads and on steeper slopes), however, some of the key drivers of poverty differ in important ways from global and previous country-level observations. Importantly, we key find differences from previous country-level and global studies which indicate that evidence from single country or global studies are likely not generalizable across countries.

The fact that our results exhibit subtle differences to previous results implies that the external validity of our, and other studies of this ilk, is likely limited. Indeed, we believe that comprehensive understanding of the socioeconomic impacts for protected areas requires that the scientific body of knowledge be built on a country-by-country basis.

Further studies in Bolivia and elsewhere should strive to identify and quantify the mechanisms through which protected areas affect poverty (e.g., Hanauer (2011); Robalino and Villalobos-Fiatt (2010)). Although studies such as ours are important for building an understanding of the global impacts of protected areas, only by understanding how protected areas affect poverty (especially in terms of alleviating poverty) can social policies be designed to enhance (mitigate) the positive (negative) impacts of protected areas. In addition, because the theme of protection in Bolivia has been toward integrated management and recognition of indigenous populations, future studies should account for differences in protected area management practices and baseline populations. 


\section{A Appendix}

\section{A.1 Threshold Analyses}

In our primary specifications we designate a municipality as protected if at least $10 \%$ of its area is occupied by a protected area. A $10 \%$ protection threshold is in line with the goals set forth at the $4^{\text {th }}$ World Congress on National Parks and Protected areas (Andam et al. 2010 23 and previous studies (Andam et al., 2010; Ferraro and Hanauer, 2011; Ferraro et al., 2011). However, it could be argued that this threshold is somewhat arbitrary. We, therefore, test the robustness of our results to changes in this threshold assignment.

Table A 1 provides comparisons of ATT for the primary genetic matching specification at the $5 \%, 10 \%$ (primary specification in main analysis), 20\%, 30\% and 50\% protection thresholds for both PI and NBI (Tables A 2 - A 5 provide full results for all protection thresholds). Table A 1 shows that as the protection threshold increases, i.e., as we increase the protected area land coverage required for a municipality to be considered protected, the number of protected municipalities drops (as expected). In the final 50\% threshold specification, only 18 (17) treated units remain in the PI (NBI) analyses.

In the PI analyses we find that the ATT remains relatively stable, and statistically significant, across the range of protection thresholds. The mean outcomes for treated and control groups jumps up (in absolute terms) at the $50 \%$ threshold providing indication that there is somewhat lower poverty within municipalities with greater area protected (note that their matched counterparts have relatively low average poverty levels as well). We see a similar phenomenon in the NBI analyses in Table A1. The lowest average poverty outcomes (for protected and matched unprotected units) are observed at the highest levels of protection. The ATT according to NBI is increasing monotonically (in absolute terms) with percent protection, however none of the estimates are significant at the $5 \%$ level (the $50 \%$ threshold specification is significant at the $10 \%$ level).

The results in Tables A $1-A 5$ provide evidence that our primary results are not driven by the choice of threshold. Rather, our results are robust and consistent across protection threshold specifications.

\footnotetext{
${ }^{23}$ As mentioned in the main text, one of the goals set forth by the $4^{\text {th }}$ World Congress on National Parks and Protected areas was to protect $10 \%$ of the earth's ecosystems by the year 2000 .
} 


\section{A.2 Placebo Analysis}

In our main and ancillary analyses we show that the estimated poverty alleviation associated with the establishment of protected areas is robust to a number of econometric specifications and ancillary analyses. However, there is always the concern that the difference in outcomes between protected and unprotected municipalities stems from our inability to select a control group that closely enough resembles the protected group 24 To address this potential confounding issue we perform a placebo analysis.

The goal is to see if our covariates of interest perform well in the construction of a counterfactual for municipalities that are observably similar (on average) to protected municipalities, but were never protected. In other words, to see if the gap in poverty outcomes between protected and unprotected groups was due to something other than protection. If protection was the only remaining source of variation across treatment arms (to which the treatment effect can be attributed) in our main analyses, then we should observe no difference in expected outcomes between the placebo group and its matched controls (i.e., our covariates are creating a quality counterfactual).

We proceed by selecting a placebo group that is observably similar to the original protected group. We then run the same genetic matching specification, assigning the placebo group as the "treated" group, as in the primary matching analysis. The placebo group in this analysis comprises the 56 matched controls from the primary genetic matching analysis in the main text ${ }^{25}$ This group is observably similar to the original protected group (on average; see Table 5) with the exception that the placebo group was not affected by protected areas. Therefore, if our covariates are capturing underlying poverty trajectories well, then by selecting unprotected municipalities that are observably similar to our placebo group, we should observe no difference in outcomes because there is no longer protection as a source of variation between the two groups.

The results in Table $\mathrm{A} 6$, for both the full and unique placebo groups, indicate that there is no placebo effect. In other words, our covariates of interest appear to be predicting poverty trajectories well (see Tables A 7 and A8 for balance results). These results buttress our claims that the treatment

\footnotetext{
${ }^{24}$ This concern is unlikely true given the high degree of balance across treatment arms in Tables 1 and 6 .

${ }^{25}$ Recall that matching was performed with replacement so the placebo group has 15 repeat observations. We choose this for our primary placebo group because it most closely resembles our original protected group in expectation. We perform an additional analysis assigning only unique matched controls, from the original analysis, to the placebo group (see Table A7).
} 
effects present in our main analyses are due to the establishment of protected areas rather than an inability to estimate quality counterfactuals.

\section{A.3 Spillover Analysis}

The central result from our main analyses is that municipalities that were affected by protected areas had differentially greater poverty reduction than comparable municipalities that were unaffected by protected areas. An often voiced concern is that protected areas, rather than having a positive impact of proximal populations, caused those most negatively impacted to emigrate from the impacted communities, thus leading to positive impact estimates. If such emigration was undertaken by relatively poor populations (a supposition supported by Robalino, 2007) it would have two effects. First, the departure of a relatively poor population would result in a decrease in the measured average poverty level within protected municipalities. Second, immigration of these relatively poor populations would increase average poverty measured in surrounding municipalities. The former affect is a concern because it implies that there were no truly positive mechanisms through which protected areas affected poverty (e.g., tourism, infrastructure development, ecosystem services, etc.). Instead, the former implies that the establishment of protected areas didn't make surrounding populations better-off, it just compelled those that they made the worst-off, to emigrate. In conjunction, such a scenario would lead to erroneous estimates of poverty alleviation associated with the establishment of protected areas. To test for this potential false identification we first assume that if the poor are negatively affected by protected areas, they will migrate to the nearest unaffected municipalities.

Our analysis to test local migration effects is thus framed as a spillover analysis. Using GIS we select all the municipalities that neighbor (congruent to) municipalities with at least $10 \%$ of their area occupied by a protected area (see Figure A 1 ). If protected areas caused poor populations to migrate to surrounding municipalities, then we would expect an increase in poverty between 1992 and 2001 in these neighboring municipalities, compared to observably similar (unprotected) municipalities. To test this hypothesis we treat the 99 neighboring municipalities ${ }^{26}$ as "treated" units and match them to observably similar unprotected municipalities (according to our covariates

\footnotetext{
${ }^{26}$ There are 116 municipalities that are congruent to a protected municipality. 17 are dropped from the sample because they are considered marginally protected.
} 
of interest). Under the null hypothesis of no spillover, there should be no treatment effect in the resulting matched sample. In other words, there should be no difference in poverty outcomes between congruent (to protected municipalities) and matched unprotected municipalities.

We run our primary genetic matching and regression specifications on the spillover data, the results of which can be found in Table A 9 (see Tables A 10 and A 11 for balance results). We find no evidence of negative spillover effects from protected municipalities into congruent municipalities. For both specifications in which we designate the PI as the outcome, the estimated impacts are quite small and statistically insignificant. In the specifications using NBI, we find estimates of poverty alleviation in congruent municipalities (compared to similar unprotected municipalities). These results are statistically significant (insignificant) in the regression (genetic matching) specification.

The results from our spillover analysis indicate that municipalities congruent to protected municipalities fared no worse (and by most indications, better) than similar unprotected municipalities. We, therefore, propose that the positive poverty impacts associated with the establishment of protected areas are unlikely due to the emigration of poor populations to surrounding communities. While this proposition may hold for our regional spillover analysis, it is difficult to test for broader general equilibrium migration effects.

One final piece of evidence that indicates our results are unlikely driven by complex migration patterns comes from the preceding placebo analysis. Aside from localized (congruent) migration, it is not illogical to presume that adversely affected poor populations might migrate to municipalities that are observably similar to the protected municipalities from which they originate. Under this scenario we might reasonably assume that poor populations would migrate to the unprotected municipalities found in the matched control group from the primary genetic matching specification. However, these are the municipalities that compose our "treated" placebo group, for which we found no difference in poverty outcomes (compared to similar unprotected municipalities) in the placebo analysis. If our more complex migration scenario were occurring, we would expect to find a negative (poverty exacerbation) treatment effect in the placebo analysis.

Unfortunately it is not possible to fully capture all the potential general equilibrium poverty effects of protected areas. However, given the limited mobility of poor populations and migration scenarios explored, we believe that our analyses provide strong evidence that the positive impacts of protected areas are not driven by the emigration of poor populations. 


\section{A.4 Areas Formally Protected in the 1990s}

Fundamental to our identification of the impacts of protected areas in our study period was Law 1333 and the associated restructuring and enforcement or protected areas subsequent to 1992. Despite the evidence of that protected areas were so-called "paper parks" (e.g., (Bruner et al., 2001)), if the 10 protected areas that were established prior to our study period were in fact effective, this may be biasing our results.

There are a number of plausible impacts to our results that stem from including protected areas established (and maintained effectively) prior to our study period. However, our primary concern is that such inclusion would significantly increase the probability of inferring poverty alleviation associated with the establishment of protected areas. To address this potential bias, we drop the 10 protected areas that were originally established prior to our study period. We are left with 32 (30) protected municipalities when the PI (NBI) is used as the outcome of interest. We run our primary specifications on this sample and find the results to be strikingly similar to those from the original sample (see Table A 12 for results and Tables A1 13 and A 14 for balance results).

\section{A.5 Rosenbaum Bounds}

The ATT estimates from the primary genetic matching specifications represent unbiased estimates of the impact of protected areas on poverty under the assumption that we have sufficiently controlled for all covariates that jointly determine the spatial establishment of protection and poverty (conditional independence assumption). However, if there exists an unobserved covariate or group of covariates, that is highly correlated with protection and poverty, and uncorrelated with the covariates for which we do control, then we may be concerned that this confounder might be biasing our results. The fundamental concern is that the poverty alleviation observed in protected municipalities is due to systematic differences between protected and unprotected municipalities, other than protection.

One of the desirable properties of matching is that under CIA we can invoke many of the methods of inference used in a randomized experiment. Under pure randomization each selected unit has an equal probability of being assigned to the treatment or control group. Therefore, under the null hypothesis of no treatment effect there is a $\operatorname{Pr}=0.5$ that any unit within a pair chosen 
across treatment arms has a greater outcome than the other unit within the pair (outcomes are "exchangeable" within pairs). In other words, under randomization, if treatment has no effect, we should observe treated units within pairs exhibiting greater outcomes approximately $50 \%$ of the time, and control units exhibiting greater outcomes approximately $50 \%$ of the time ${ }^{27}$ If matching satisfies CIA then similar logic, and inference, can be applied to matched pairs.

Suppose that matching perfectly accounts for all covariates that affect outcome and selection. Similar to randomization, under the null hypothesis of no treatment effect, we should observe treated units exhibiting greater outcome values within matched pairs approximately $50 \%$, and vice versa. This type of inference is valid within matched pairs because, conditional on covariates $X$, the probability of treatment within these pairs in equal and, therefore, outcomes within matched pairs are considered exchangeable ${ }^{28}$ Now suppose that there is some unobserved covariate, $u$, that is uncorrelated with $X$, but correlated with outcomes $Y$ and treatment $T$. There are two ways of looking at the impact of $u$ on inference: (1) $u$ affects the probability of treatment such that exchangeability is no longer satisfied, therefore, invalidating permutation-based inference using a null of no treatment effect, and; (2) the differences in $u$, which are systematically related to $T$, are driving the observed differences in $Y$, otherwise attributed to $T$.

Rosenbaum (2002) proposes measures by which we can test the sensitivity of our matching results to the presence of $u$. Rosenbaum bounds allow us to measure how strong a confounder, $u$, would need to be to the invalidate our statistical findings 29 In Rosenbaum's model the probability of assignment to treatment $\pi_{j}$ for unit $j$ can be expressed in terms of odds as $\frac{\pi_{j}}{\left(1-\pi_{j}\right)}$. Under randomization $\pi_{j}=\pi_{k}$ for $j \neq k$. Similarly, in an observational setting and in absence of $u$, $\pi_{j}=\pi_{k}$ when $x_{j}=x_{k}$. In other words, conditional of similar values of $X$ within matched pairs, the probability of treatment is equal for treated and control units. The departure from randomization (or the influence of $u$ ), can be expressed by $\Gamma$ in the odds ratio between matched pairs

$$
\frac{1}{\Gamma} \leq \frac{\pi_{j}\left(1-\pi_{k}\right)}{\pi_{k}\left(1-\pi_{j}\right)} \leq \Gamma, \text { for all } j, k \text { with } x_{j}=x_{k},
$$

\footnotetext{
${ }^{27}$ Under randomization, there are a number of permutation-based inference tests by which to estimate exact p-values based on this logic (e.g., Rosenbaum 2002).

${ }^{28}$ Another way of expressing this is that, conditional of $X$, there remains no other source of variation between treated and control groups that affects $Y$, other than $T$.

${ }^{29}$ It should be noted prior to exposition that any measurement of sensitivity to unobserved bias, or varying degrees therein, does not imply the presences of unobserved bias.
} 
where $\Gamma=1$ under randomization. Conversely, if $x_{j}=x_{k}$ but $\pi_{j} \neq \pi_{k}$ this implies the presence of $u$, the degree of which is captured by $\Gamma \neq 1$. For instance, if $\Gamma=2$ (but $x_{j}=x_{k}$ ) this implies that the presence of $u$ is causing the odds of treatment between $j$ and $k$ to differ by a factor of 2 . In Rosenbaum's sensitivity test we ask how large $\Gamma$ would need to be (i.e., how strong a confounder $u$ would need to be) in order to alter matching-based inference.

To frame $\Gamma$ explicitly in terms of the unobserved bias, $u$, Rosenbaum (2002) shows that the log odds ratio for $j$ is equivalent to

$$
\log \left(\frac{\pi_{j}}{\left(1-\pi_{j}\right)}\right)=k\left(x_{j}\right)+\gamma u_{j}, \text { with } 0 \leq u_{j} \leq 1
$$

which states that the odds of treatment are an unknown function of $x$ plus an unknown parametrization of $u 30$ The odds ratio can therefore be rewritten as

$$
\frac{\pi_{j}\left(1-\pi_{k}\right)}{\pi_{k}\left(1-\pi_{j}\right)}=\exp \left\{\gamma\left(u_{j}-u_{k}\right)\right\}
$$

where $k(\cdot)$ cancels when $x_{j}=x_{k}$. By stating the odds ratio in terms of $u$ it can be seen that in the absence of $u$, i.e., when $u$ does not influence $\pi$ (or when $u_{j}=u_{k}$ ), $e^{\gamma}=\Gamma=1$. Conversely, as the influence of $u$ increases (or as $u_{j}$ and $u_{k}$ diverge) $\Gamma$ and the absolute difference in probability of treatment between treated and untreated units increases.

In observational studies we cannot observe the presence of $u$ or its potential influence as measured by $\Gamma=e^{\gamma}$. In Rosenbaum's sensitivity test we impose increasing levels of $\Gamma$ to measure at what influence of unobserved bias our inference would be invalidated (shown to be insignificant). If inference is altered by a level of $\Gamma$ close to 1 this implies that a study is sensitive to unobserved bias. However, we reiterate that estimated sensitivity to unobserved bias in no way implies the presence of unobserved bias.

\section{A.6 Heterogeneous Impacts}

One of the primary goals of the 1992 protected area restructuring was to empower affected communities by allowing for an integrated management strategy. Proponents of integrated management

\footnotetext{
${ }^{30}$ See Rosenbaum (2002) for a discussion of the restriction on $u$.
} 
argue that such a strategy is necessary for environmental goals to be achieved. Furthermore, by promoting community involvement toward the achievement of environmental goals, one might expect to see greater participation in the community at large and, therefore, greater poverty reductions in communities surrounding protected areas that subscribe to an integrated management policy.

We test for differential poverty impacts in municipalities that were impacted by integrated management protected areas (IMPA) ${ }^{31}$ using analyses similar to our primary specifications. Of the 56 municipalities considered protected in the primary analyses, 18 are considered protected by IMPAs. The genetic matching specifications return ATT estimates of -0.49 and -7.36 for PI and NBI, respectively. These point estimates provide no evidence of a differential poverty reduction in communities affected by IMPAs. However, the fact that both of these estimates are highly significant (p-values of 0.0006 and 0.004 , respectively) with such a small sample is indicative of the consistency of poverty alleviating effects associated with IMPAs. In the end, such an analysis of heterogeneity would significantly benefit from finer socioeconomic data. We believe that defensible evidence of heterogeneity will only be obtained from community-level data, which will likely be attainable in future work.

\footnotetext{
${ }^{31}$ Municipalities considered protected in these analyses had at least $10 \%$ of their area occupied by an IMPA.
} 


\section{References}

Abadie, A., D. Drukker, J. Herr, and G. Imbens (2004). Implementing matching estimators for average treatment effects in stata. Stata Journal 4, 290-311.

Abadie, A. and G. Imbens (2006). Large sample properties of matching estimators for average treatment effects. Econometrica 74(1), 235-267.

Adams, W., R. Aveling, D. Brockington, B. Dickson, J. Elliott, J. Hutton, D. Roe, B. Vira, and W. Wolmer (2004). Biodiversity conservation and the eradication of poverty. Science 306(5699), $1146-1149$.

Andam, K., P. Ferraro, K. Sims, A. Healy, and M. Holland (2010). Protected areas reduced poverty in costa rica and thailand. Proceedings of the National Academy of Sciences 107(22), 9996.

Andam, K. S., P. J. Ferraro, A. Pfaff, G. Sanchez-Azofeifa, and J. A. Robalino (2008). Measuring the effectiveness of protected area networks in reducing deforestation. Proceedings of the National Academy of Sciences 105(42), 16089-16094.

Angrist, J. and J. Pischke (2009). Mostly harmless econometrics: an empiricist's companion. Princeton Univ Pr.

Bruner, A., R. Gullison, R. Rice, and G. Da Fonseca (2001). Effectiveness of parks in protecting tropical biodiversity. Science 291(5501), 125.

Canavire-Bacarreza, G. and M. Mariscal (2010). Políticas Macroeconómicas, Choques Externos y Protección Social En Bolivia.

Cavatassi, R., B. Davis, and L. Lipper (2004). Estimating poverty over time and space: construction of a time-variant poverty index for costa rica. Technical report, ESA Working Paper.

Coad, L., A. Campbell, L. Miles, and K. Humphries (2008). The costs and benefits of protected areas for local livelihoods: a review of the current literature.

Cohen, J. (1988). Statistical power analysis for the behavioral sciences. Lawrence Erlbaum.

Dehejia, R. and S. Wahba (2002). Propensity score-matching methods for nonexperimental causal studies. Review of Economics and Statistics 84(1), 151-161.

Duffy-Deno, K. (1998). The effect of federal wilderness on county growth in the intermountain western united states. Journal of Regional Science 38(1), 109-136.

Ferraro, P. J. (2008). Protected areas and human well-being.

Ferraro, P. J. and M. M. Hanauer (2011). Protecting ecosystems and alleviating poverty with parks and reserves: 'win-win' or tradeoffs? Environmental and Resource Economics. 48(2), 269.

Ferraro, P. J., M. M. Hanauer, and K. R. Sims (2011). Conditions associated with protected area success in conservation and poverty reduction. Proceedings of the National Academy of Sciences. Forthcoming.

Filmer, D. and L. Pritchett (2001). Estimating wealth effects without expenditure dataor tears: An application to educational enrollments in states of india*. Demography 38(1), 115-132. 
Fleck, L. C., M. Amend, L. Painter, and J. Reid (2006). Regional economic benefits from condercation: The cas of madidi. Conservation Strategy Fund.

Hanauer, M. M. (2011). Causal mechanisms of protected area impacts. Working Paper.

Ho, D., K. Imai, G. King, and E. Stuart (2007). Matching as nonparametric preprocessing for reducing model dependence in parametric causal inference. Political Analysis 15, 199-236.

Holland, P. (1986). Statistics and causal inference. Journal of the American Statistical Association 81(396), 945-960.

Imbens, G. and J. Wooldridge (2009). Recent developments in the econometrics of program evaluation. Journal of Economic Literature 47(1), 5-86.

Joppa, L. and A. Pfaff (2009). High and far: Biases in the location of protected areas. PLOS One $4(12)$.

Lewis, D., G. Hunt, and A. Plantinga (2002). Public conservation land and employment growth in the northern forest region. Land Economics 78(2), 245.

Lewis, D., G. Hunt, and A. Plantinga (2003). Does public lands policy affect local wage growth? Growth and Change 34(1), 64-86.

MEA (2005). Ecosystems and human well-being. Millennium Ecosystem Assessment. Island Press.

Meyer, B. (1995). Natural and quasi-experiments in economics. Journal of Business and Economic Statistics 13(2), 151-161.

Pfaff, A., J. Robalino, G. Sanchez-Azofeifa, K. Andam, and P. Ferraro (2009). Park location affects forest protection: Land characteristics cause differences in park impacts across costa rica. The B.E. Journal of Economic Analysis and Policy 9(2), 5.

Robalino, J. (2007). Land conservation policies and income distribution: who bears the burden of our environmental efforts? Environment and Development Economics 12(04), 521-533.

Robalino, J. and L. Villalobos-Fiatt (2010). Conservation policies and labor markets: Unraveling the effects of national parks on local wages in costa rica. IDEAS Discussion Papers.

Rosenbaum, P. (2002). Observational studies. Springer.

Sachs, J., J. Baillie, W. Sutherland, P. Armsworth, N. Ash, J. Beddington, T. Blackburn, B. Collen, B. Gardiner, and K. Gaston (2009). Biodiversity conservation and the millennium development goals. Science 325(5947), 1502.

Sekhon, J. (2007). Multivariate and propensity score matching software with automated balance optimization: The matching package for r. Journal of Statistical Software 10(2), 1-51.

Sims, K. R. (2010). Conservation and development: Evidence from thai protected areas. Journal of Environmental Economics and Management 60(2), 94-114.

Watts, R., R. Compton, J. McCammon, C. Rich, S. Wright, T. Owens, and D. Ouren (2007). Roadless space of the conterminous united states. Science 316(5825), 736.

WDPA (2011). World database on protected areas: 2010 annual release. 
Wilkie, D., G. Morelli, J. Demmer, M. Starkey, P. Telfer, and M. Steil (2006). Parks and people: Assessing the human welfare effects of establishing protected areas for biodiversity conservation. Conservation Biology 20(1), 247.

Yáñez, E. (2006). Existe un vinculo entre las areas protigidas y la pobreza? evidencia de tres areas protegidas de bolivia. The Nature Conservancy Mimeo. 


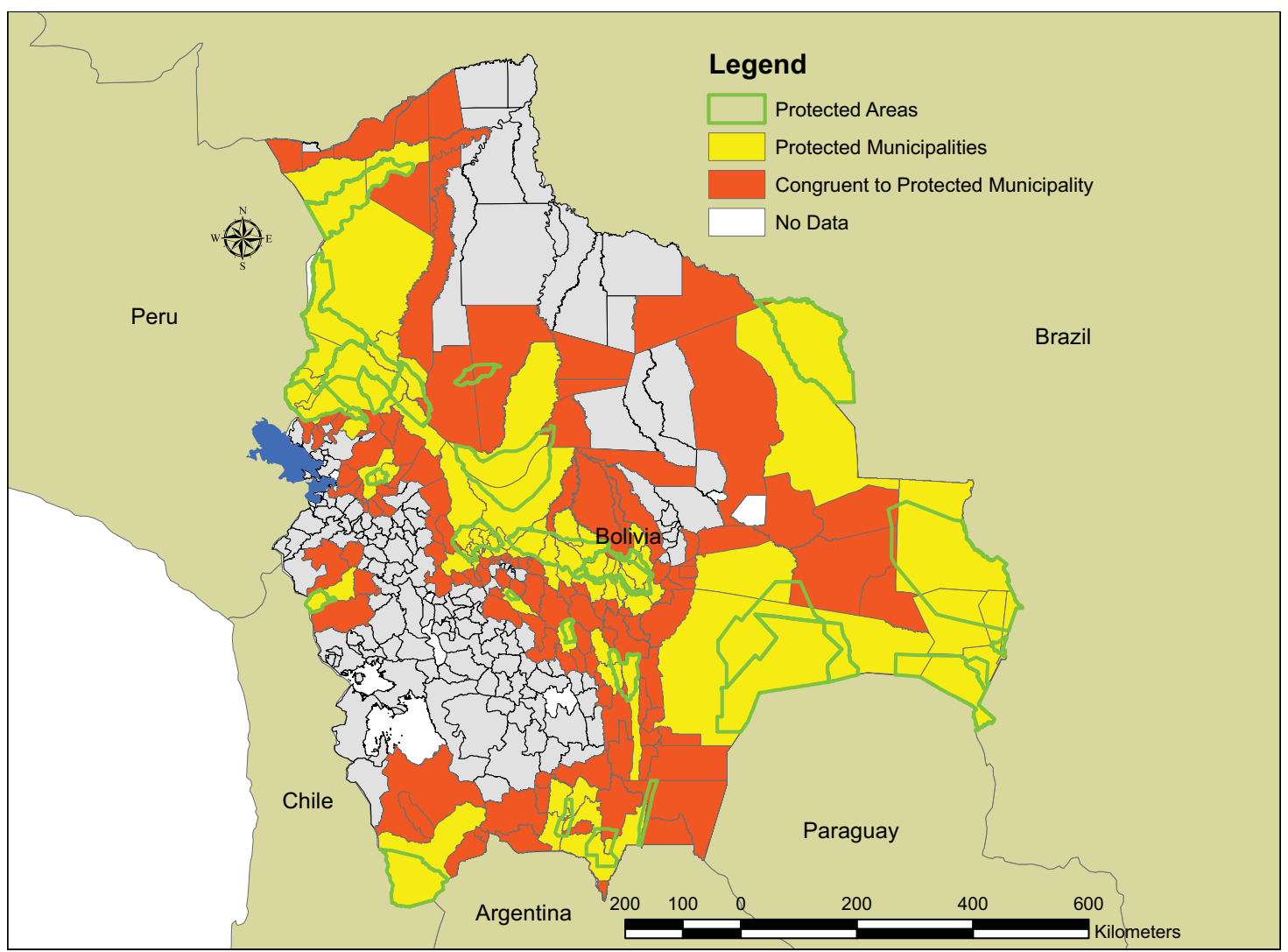

Figure A1: Map of municipalities congruent (orange) to a municipality with at least $10 \%$ area occupied by a protected area (yellow). 

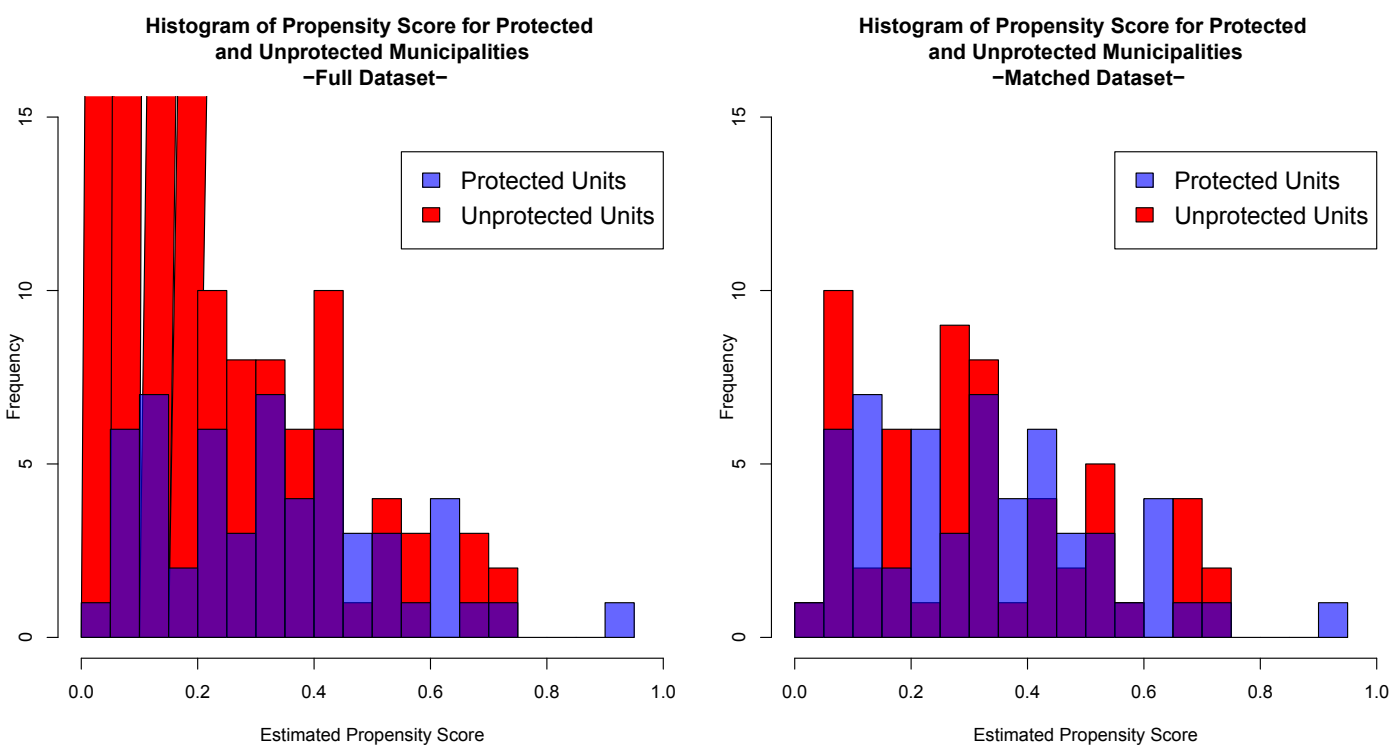

Figure A2: Histogram of propensity score distributions according to PI for full and matched datasets. Red bars indicate frequency of unprotected units and blue bars indicate frequency of protected units (purple represent areas where bars overlap).

Table A1: ATT Estimates from Primary GenMatch Specification by Protection Threshold

\begin{tabular}{cccccccc}
\hline \multirow{2}{*}{ Threshold } & \multicolumn{3}{c}{ Poverty Index } & & \multicolumn{3}{c}{ NBI } \\
\cline { 2 - 3 } \cline { 7 - 8 } & $\mathrm{Y}(\mathrm{T}=1)$ & $\mathrm{Y}(\mathrm{T}=0)$ & Treatment & & $\mathrm{Y}(\mathrm{T}=1)$ & $\mathrm{Y}(\mathrm{T}=0)$ & Treatment \\
\hline \hline $5 \%$ & -1.23 & -0.761 & -0.465 & & 77.12 & 81.78 & -4.66 \\
& {$[63]$} & {$[63]$} & $(0.136)$ & & {$[60]$} & {$[60]$} & $(3.394)$ \\
$10 \%$ & -1.33 & -0.805 & -0.525 & & 76.18 & 84.16 & -4.99 \\
(Primary Specification) & {$[56]$} & {$[56]$} & $(0.142)$ & & {$[53]$} & {$[53]$} & $(3.67)$ \\
$20 \%$ & -1.214 & -0.725 & -0.489 & & 76.21 & 82.3 & -6.075 \\
& {$[42]$} & {$[42]$} & $(0.149)$ & & {$[39]$} & {$[39]$} & $(4.75)$ \\
$30 \%$ & -1.162 & -0.731 & -0.431 & & 76.64 & 82.92 & -6.282 \\
& {$[38]$} & {$[38]$} & $(0.154)$ & & {$[36]$} & {$[36]$} & $(5.1)$ \\
$50 \%$ & -1.67 & -1.223 & -0.454 & & 70.14 & 76.49 & -6.35 \\
& {$[18]$} & {$[18]$} & $(0.272)$ & & {$[17]$} & {$[17]$} & $(3.52)$ \\
\hline \hline
\end{tabular}

(Abadie-Imbens Heteroskedasticity Robust Standard Errors)

[Observation] 
Table A2: Results from Primary and Ancillary Analyses, Treatment Threshold=5\%

\begin{tabular}{lccccccc}
\hline \multirow{2}{*}{ Method } & \multicolumn{3}{c}{ Poverty Index } & & \multicolumn{3}{c}{ NBI } \\
\cline { 2 - 3 } \cline { 6 - 7 } & $\mathrm{Y}(\mathrm{T}=1)$ & $\mathrm{Y}(\mathrm{T}=0)$ & Treatment & & $\mathrm{Y}(\mathrm{T}=1)$ & $\mathrm{Y}(\mathrm{T}=0)$ & Treatment \\
\hline \hline Nave Difference & -1.23 & -0.4946 & -0.731 & & 77.12 & 85.89 & -8.77 \\
in Means & {$[63]$} & {$[261]$} & $\{0.0215\}$ & & {$[60]$} & {$[251]$} & $\{0.004\}$ \\
Regression Dropping & $\mathrm{NA}$ & $\mathrm{NA}$ & -0.42 & & $\mathrm{NA}$ & $\mathrm{NA}$ & -2.04 \\
Marginal & {$[63]$} & {$[46]$} & $(0.103)$ & & {$[60]$} & {$[42]$} & $(1.55)$ \\
Post-Match Frequency & -1.23 & -0.761 & -0.465 & & 77.12 & 81.78 & -4.66 \\
Weighted Regression & {$[63]$} & {$[63]$} & $(0.136)$ & & {$[60]$} & {$[60]$} & $(3.394)$ \\
Genetic Matching & -0.986 & -0.516 & -0.471 & & 79.72 & 82.73 & -3.01 \\
& {$[56]$} & {$[56]$} & $(0.14)$ & & {$[54]$} & {$[54]$} & $(2.09)$ \\
Genetic Matching, & -1.07 & -0.511 & -0.56 & & 79.04 & 81.51 & -2.47 \\
Calipers=1sd & {$[49]$} & {$[49]$} & $(0.147)$ & & {$[47]$} & {$[47]$} & $(1.55)$ \\
\hline \hline
\end{tabular}

[Number of observations]

(Standard errors)

$\{\mathrm{P}-$ value $\}$

Table A3: Results from Primary and Ancillary Analyses, Treatment Threshold=20\%

\begin{tabular}{lccccccc}
\hline \multirow{2}{*}{ Method } & \multicolumn{3}{c}{ Poverty Index } & & \multicolumn{3}{c}{ NBI } \\
\cline { 2 - 3 } \cline { 6 - 7 } & $\mathrm{Y}(\mathrm{T}=1)$ & $\mathrm{Y}(\mathrm{T}=0)$ & Treatment & & $\mathrm{Y}(\mathrm{T}=1)$ & $\mathrm{Y}(\mathrm{T}=0)$ & Treatment \\
\hline \hline Nave Difference & -1.21 & -0.551 & -0.663 & & 76.2 & 85.3 & -9.13 \\
in Means & {$[42]$} & {$[282]$} & $\{0.018\}$ & & {$[39]$} & {$[272]$} & $\{0.013\}$ \\
Regression Dropping & $\mathrm{NA}$ & $\mathrm{NA}$ & -0.527 & & $\mathrm{NA}$ & $\mathrm{NA}$ & -7.23 \\
Marginal & {$[42]$} & {$[252]$} & $(0.113)$ & & {$[39]$} & {$[242]$} & $(1.39)$ \\
Post-Match Frequency & $\mathrm{NA}$ & $\mathrm{NA}$ & -0.47 & & $\mathrm{NA}$ & $\mathrm{NA}$ & -2.83 \\
Weighted Regression & {$[42]$} & {$[31]$} & $(0.116)$ & & {$[39]$} & {$[29]$} & $(1.95)$ \\
Genetic Matching & -0.996 & -0.475 & -0.52 & & 78.95 & 82.48 & -3.53 \\
& {$[36]$} & {$[36]$} & $(0.155)$ & & {$[35]$} & {$[35]$} & $(3.1)$ \\
Genetic Matching, & -1.07 & -0.511 & -0.56 & & 79.04 & 81.51 & -2.47 \\
Calipers=1sd & {$[49]$} & {$[49]$} & $(0.147)$ & & {$[47]$} & {$[47]$} & $(1.55)$ \\
\hline \hline
\end{tabular}

[Number of observations]

(Standard errors)

$\{\mathrm{P}$-value $\}$ 
Table A4: Results from Primary and Ancillary Analyses, Treatment Threshold $=30 \%$

\begin{tabular}{lccccccc}
\hline \multirow{2}{*}{ Method } & \multicolumn{3}{c}{ Poverty Index } & & \multicolumn{3}{c}{$\mathrm{NBI}$} \\
\cline { 2 - 3 } \cline { 6 - 8 } & $\mathrm{Y}(\mathrm{T}=1)$ & $\mathrm{Y}(\mathrm{T}=0)$ & Treatment & & $\mathrm{Y}(\mathrm{T}=1)$ & $\mathrm{Y}(\mathrm{T}=0)$ & Treatment \\
\hline \hline Nave Difference & -1.16 & -0.567 & -0.595 & & 76.6 & 85.2 & -8.551 \\
in Means & {$[42]$} & {$[282]$} & $\{0.108\}$ & & {$[36]$} & {$[275]$} & $\{0.029\}$ \\
Regression Dropping & $\mathrm{NA}$ & $\mathrm{NA}$ & -0.523 & & $\mathrm{NA}$ & $\mathrm{NA}$ & -7.42 \\
Marginal & {$[38]$} & {$[252]$} & $(0.119)$ & & {$[36]$} & {$[242]$} & $(1.44)$ \\
Post-Match Frequency & $\mathrm{NA}$ & $\mathrm{NA}$ & -0.45 & & $\mathrm{NA}$ & $\mathrm{NA}$ & -2.91 \\
Weighted Regression & {$[38]$} & {$[30]$} & $(0.124)$ & & {$[36]$} & {$[28]$} & $(2.08)$ \\
Genetic Matching & -1.162 & -0.731 & -0.431 & & 76.64 & 82.92 & -6.282 \\
& {$[38]$} & {$[38]$} & $(0.154)$ & & {$[36]$} & {$[36]$} & $(5.1)$ \\
Genetic Matching, & -0.908 & -0.506 & -0.402 & & 79.71 & 83.59 & -3.872 \\
Calipers=1sd & {$[32]$} & {$[32]$} & $(0.157)$ & & {$[31]$} & {$[31]$} & $(3.1)$ \\
\hline \hline
\end{tabular}

[Number of observations]

(Standard errors)

$\{\mathrm{P}$-value $\}$

Table A5: Results from Primary and Ancillary Analyses, Treatment Threshold=50\%

\begin{tabular}{lccccccc}
\hline \multirow{2}{*}{ Method } & \multicolumn{3}{c}{ Poverty Index } & & \multicolumn{3}{c}{ NBI } \\
\cline { 2 - 3 } \cline { 6 - 7 } & $\mathrm{Y}(\mathrm{T}=1)$ & $\mathrm{Y}(\mathrm{T}=0)$ & Treatment & & $\mathrm{Y}(\mathrm{T}=1)$ & $\mathrm{Y}(\mathrm{T}=0)$ & Treatment \\
\hline \hline Nave Difference & -1.67 & -0.577 & -1.1 & & 70.14 & 85.01 & -14.87 \\
in Means & {$[18]$} & {$[306]$} & $\{0.09\}$ & & {$[17]$} & {$[294]$} & $\{0.04\}$ \\
Regression Dropping & $\mathrm{NA}$ & $\mathrm{NA}$ & -0.684 & & $\mathrm{NA}$ & $\mathrm{NA}$ & -11.3 \\
Marginal & {$[18]$} & {$[252]$} & $(0.162)$ & & {$[17]$} & {$[242]$} & $(1.95)$ \\
Post-Match Frequency & $\mathrm{NA}$ & $\mathrm{NA}$ & -0.627 & & $\mathrm{NA}$ & $\mathrm{NA}$ & -8.52 \\
Weighted Regression & {$[18]$} & {$[15]$} & $(0.218)$ & & {$[17]$} & {$[15]$} & $(3.3)$ \\
Genetic Matching & -1.67 & -1.223 & -0.454 & & 70.14 & 76.49 & -6.35 \\
& {$[18]$} & {$[18]$} & $(0.272)$ & & {$[17]$} & {$[17]$} & $(3.52)$ \\
Genetic Matching & -1.23 & -0.451 & -0.782 & & 75.9 & 82.22 & -6.33 \\
Calipers=1sd & {$[15]$} & {$[15]$} & $(0.245)$ & & {$[14]$} & {$[14]$} & $(6.95)$ \\
\hline \hline
\end{tabular}

[Number of observations]

(Standard errors)

$\{\mathrm{P}$-value $\}$

Table A6: Results from Placebo Matching Test

\begin{tabular}{cccc}
\hline & \multicolumn{3}{c}{ Poverty Index } \\
\cline { 2 - 4 } Method & $\mathrm{Y}(\mathrm{T}=1)$ & $\mathrm{Y}(\mathrm{T}=0)$ & Treatment \\
\hline \hline Genetic Matching & -0.797 & -0.84 & 0.044 \\
Full Matched Sample & {$[56]$} & {$[56]$} & $(0.17)$ \\
Genetic Matching & -0.915 & -0.7189 & -0.196 \\
Dropped Repeat & {$[41]$} & {$[41]$} & $(0.156)$ \\
\hline \hline [Number of observations] & & \\
(Standard errors) & & &
\end{tabular}


Table A7: Balance Results for Placebo Matching Analysis- Full Sample

\begin{tabular}{rrcccccc}
\hline Covariate & Status & $\begin{array}{c}\text { Mean } \\
\text { Prot. }\end{array}$ & $\begin{array}{c}\text { Mean } \\
\text { Unprot. }\end{array}$ & $\begin{array}{c}\text { Diff. } \\
\text { in Means }\end{array}$ & $\begin{array}{c}\text { Norm. } \\
\text { Diff. }{ }^{\dagger}\end{array}$ & $\begin{array}{c}\text { Mean eQQ } \\
\text { Diff. }\end{array}$ & $\begin{array}{c}\text { \%Improve } \\
\text { Mean Diff. }\end{array}$ \\
\hline \hline Poverty Index & Unmatched & 0.319 & 0.834 & -0.515 & 0.157 & 0.502 & \\
\% Forest 1992 & Matched & 0.319 & 0.264 & 0.054 & 0.016 & 0.216 & $89.48 \%$ \\
& Unmatched & 0.466 & 0.148 & 0.317 & 0.531 & 0.315 & \\
Distance to & Matched & 0.466 & 0.458 & 0.008 & 0.012 & 0.035 & $97.51 \%$ \\
Major City & Matched & 136600 & 102500 & 34100 & 0.205 & 33260 & \\
Average & 136600 & 137500 & -868.1 & 0.004 & 13100 & $97.45 \%$ \\
Elevation & Unmatched & 1794 & 2860 & -1066 & 0.375 & 1052 & \\
Average Slope & Unmatched & 1794 & 1936 & -142 & 0.051 & 204.9 & $86.68 \%$ \\
& Matched & 23.89 & 18.06 & 5.822 & 0.191 & 5.989 & \\
Roadless & Unmatched & $2.526 \mathrm{E}+14$ & $6.101 \mathrm{E}+13$ & $1.916 \mathrm{E}+14$ & 0.259 & $1.860 \mathrm{E}+14$ & \\
Volume 1992 & Matched & $2.526 \mathrm{E}+14$ & $1.269 \mathrm{E}+14$ & $1.257 \mathrm{E}+14$ & 0.162 & $1.547 \mathrm{E}+14$ & $34.38 \%$ \\
\hline \hline
\end{tabular}

${ }^{\dagger}$ Normalized difference in means is the difference in means divided by the square root of the sum of the squared standard deviations of the treated and untreated covariate samples.

$\ddagger$ Mean eQQ difference is the mean of the raw differences in the empirical quantile-quantile plots.

Table A8: Balance Results for Placebo Matching Analysis- Unique Sample

\begin{tabular}{rrcccccc}
\hline Covariate & Status & $\begin{array}{c}\text { Mean } \\
\text { Prot. }\end{array}$ & $\begin{array}{c}\text { Mean } \\
\text { Unprot. }\end{array}$ & $\begin{array}{c}\text { Diff. } \\
\text { in Means }\end{array}$ & $\begin{array}{c}\text { Norm. } \\
\text { Diff. }^{\dagger}\end{array}$ & $\begin{array}{c}\text { Mean eQQ } \\
\text { Diff. }\end{array}$ & $\begin{array}{c}\text { \%Improve } \\
\text { Mean Diff. }\end{array}$ \\
\hline \hline Poverty Index & Unmatched & 0.282 & 0.834 & -0.551 & 0.170 & 0.537 & \\
1992 & Matched & 0.282 & 0.283 & -0.001 & 0.000 & 0.188 & $99.89 \%$ \\
\% Forest 1991 & Unmatched & 0.427 & 0.148 & 0.279 & 0.458 & 0.274 & \\
& Matched & 0.427 & 0.426 & 0.002 & 0.002 & 0.024 & $99.41 \%$ \\
Distance to & Unmatched & 136100 & 102500 & 33560 & 0.201 & 32230 & \\
Major City & Matched & 136100 & 132900 & 3230 & 0.017 & 10430 & $90.38 \%$ \\
Average & Unmatched & 1956 & 2860 & -904.1 & 0.313 & 887.6 & \\
Elevation & Matched & 1956 & 2000 & -44.070 & 0.015 & 147.3 & $95.13 \%$ \\
Average Slope & Unmatched & 23.62 & 18.06 & 5.556 & 0.181 & 5.591 & \\
& Matched & 23.62 & 23.03 & 0.594 & 0.017 & 3.361 & $89.30 \%$ \\
Roadless & Unmatched & $1.992 \mathrm{E}+14$ & $6.101 \mathrm{E}+13$ & $1.382 \mathrm{E}+14$ & 0.212 & $1.265 \mathrm{E}+14$ & \\
Volume 1992 & Matched & $1.992 \mathrm{E}+14$ & $1.415 \mathrm{E}+14$ & $5.764 \mathrm{E}+13$ & 0.080 & $1.097 \mathrm{E}+14$ & $58.28 \%$ \\
\hline \hline
\end{tabular}

${ }^{\dagger}$ Normalized difference in means is the difference in means divided by the square root of the sum of the squared standard deviations of the treated and untreated covariate samples.

¥ Mean eQQ difference is the mean of the raw differences in the empirical quantile-quantile plots.

Table A9: Spillover Analyses, Municipalities Congruent to Protected Municipalities Considered Treated

\begin{tabular}{lccccccc}
\hline & \multicolumn{3}{c}{ Poverty Index } & & \multicolumn{3}{c}{ NBI } \\
\cline { 2 - 3 } \cline { 6 - 8 } \multicolumn{1}{c}{ Method } & $\mathrm{Y}(\mathrm{T}=1)$ & $\mathrm{Y}(\mathrm{T}=0)$ & Treatment & & $\mathrm{Y}(\mathrm{T}=1)$ & $\mathrm{Y}(\mathrm{T}=0)$ & Treatment \\
\hline \hline Regression Dropping & $\mathrm{NA}$ & $\mathrm{NA}$ & -0.14 & & $\mathrm{NA}$ & $\mathrm{NA}$ & -3.12 \\
Marginal & {$[99]$} & {$[153]$} & $(0.09)$ & & {$[95]$} & {$[147]$} & $(0.98)$ \\
Genetic Matching & -0.629 & -0.726 & 0.097 & & 81.7 & 83.88 & -2.187 \\
& {$[99]$} & {$[99]$} & $(0.185)$ & & {$[95]$} & {$[95]$} & $(2.29)$ \\
\hline \hline
\end{tabular}

[Number of observations]

(Standard errors) 
Table A10: Balance Results for Congruent Spillover Analysis- PI

\begin{tabular}{|c|c|c|c|c|c|c|c|}
\hline Covariate & Status & $\begin{array}{l}\text { Mean } \\
\text { Prot. }\end{array}$ & $\begin{array}{c}\text { Mean } \\
\text { Unprot. }\end{array}$ & $\begin{array}{c}\text { Diff. } \\
\text { in Means }\end{array}$ & $\begin{array}{l}\text { Norm. } \\
\text { Diff. }^{\dagger}\end{array}$ & $\begin{array}{c}\text { Mean eQQ } \\
\text { Diff. }^{\ddagger}\end{array}$ & $\begin{array}{l}\text { \%Improve } \\
\text { Mean Diff. }\end{array}$ \\
\hline Poverty Index & Unmatched & 0.678 & 0.787 & -0.109 & 0.034 & 0.323 & \\
\hline 1992 & Matched & 0.678 & 0.616 & 0.062 & 0.019 & 0.331 & $43.27 \%$ \\
\hline \multirow[t]{2}{*}{ \% Forest 1991} & Unmatched & 0.319 & 0.113 & 0.206 & 0.355 & 0.208 & \\
\hline & Matched & 0.319 & 0.311 & 0.008 & 0.012 & 0.020 & $96.30 \%$ \\
\hline Distance to & Unmatched & 109000 & 107400 & 1569 & 0.009 & 10650 & \\
\hline Major City & Matched & 109000 & 110500 & -1567 & 0.009 & 9140 & $0.06 \%$ \\
\hline Average & Unmatched & 2124 & 3095 & -970.3 & 0.342 & 959.5 & \\
\hline Elevation & Matched & 2124 & 2109 & 15.45 & 0.005 & 195.9 & $98.41 \%$ \\
\hline \multirow[t]{2}{*}{ Average Slope } & Unmatched & 21.66 & 17.23 & 4.43 & 0.145 & 4.688 & \\
\hline & Matched & 21.66 & 20.70 & 0.96 & 0.029 & 3.121 & $78.28 \%$ \\
\hline Roadless & Unmatched & $7.926 \mathrm{E}+13$ & $8.624 \mathrm{E}+13$ & $-6.976 \mathrm{E}+12$ & 0.009 & $3.20 \mathrm{E}+13$ & \\
\hline Volume 1992 & Matched & $7.926 \mathrm{E}+13$ & $7.774 \mathrm{E}+13$ & $1.524 \mathrm{E}+12$ & 0.002 & $1.95 \mathrm{E}+13$ & $78.15 \%$ \\
\hline
\end{tabular}

Table A11: Balance Results for Congruent Spillover Analysis- NBI

\begin{tabular}{|c|c|c|c|c|c|c|c|}
\hline Covariate & Status & $\begin{array}{l}\text { Mean } \\
\text { Prot. }\end{array}$ & $\begin{array}{c}\text { Mean } \\
\text { Unprot. }\end{array}$ & $\begin{array}{c}\text { Diff. } \\
\text { in Means }\end{array}$ & $\begin{array}{l}\text { Norm. } \\
\text { Diff. }^{\dagger}\end{array}$ & $\begin{array}{l}\text { Mean eQQ } \\
\text { Diff. }^{\dagger}\end{array}$ & $\begin{array}{l}\text { \%Improve } \\
\text { Mean Diff. }\end{array}$ \\
\hline NBI 1992 & $\begin{array}{r}\text { Unmatched } \\
\text { Matched }\end{array}$ & $\begin{array}{l}89.760 \\
89.760\end{array}$ & $\begin{array}{l}91.880 \\
90.560\end{array}$ & $\begin{array}{l}-2.114 \\
-0.797\end{array}$ & $\begin{array}{l}0.049 \\
0.018\end{array}$ & $\begin{array}{l}1.957 \\
1.936\end{array}$ & $62.32 \%$ \\
\hline \% Forest 1991 & $\begin{array}{r}\text { Unmatched } \\
\text { Matched }\end{array}$ & $\begin{array}{l}0.309 \\
0.309\end{array}$ & $\begin{array}{l}0.108 \\
0.304\end{array}$ & $\begin{array}{l}0.201 \\
0.005\end{array}$ & $\begin{array}{l}0.346 \\
0.007\end{array}$ & $\begin{array}{l}0.203 \\
0.023\end{array}$ & $97.56 \%$ \\
\hline $\begin{array}{l}\text { Distance to } \\
\text { Major City }\end{array}$ & $\begin{array}{r}\text { Unmatched } \\
\text { Matched }\end{array}$ & $\begin{array}{l}109200 \\
109200\end{array}$ & $\begin{array}{l}108200 \\
107300\end{array}$ & $\begin{array}{l}1048 \\
1894\end{array}$ & $\begin{array}{l}0.006 \\
0.011\end{array}$ & $\begin{array}{c}10110 \\
7354\end{array}$ & $-80.79 \%$ \\
\hline $\begin{array}{r}\text { Average } \\
\text { Elevation }\end{array}$ & $\begin{array}{r}\text { Unmatched } \\
\text { Matched }\end{array}$ & $\begin{array}{l}2158 \\
2158\end{array}$ & $\begin{array}{l}3135 \\
2137\end{array}$ & $\begin{array}{l}-977 \\
20.97\end{array}$ & $\begin{array}{l}0.348 \\
0.008\end{array}$ & $\begin{array}{l}965.8 \\
167.7\end{array}$ & $97.85 \%$ \\
\hline Average Slope & $\begin{array}{r}\text { Unmatched } \\
\text { Matched }\end{array}$ & $\begin{array}{l}22.08 \\
22.08\end{array}$ & $\begin{array}{l}17.75 \\
22.72\end{array}$ & $\begin{array}{c}4.332 \\
-0.643\end{array}$ & $\begin{array}{l}0.141 \\
0.019\end{array}$ & $\begin{array}{l}4.579 \\
2.743\end{array}$ & $85.15 \%$ \\
\hline $\begin{array}{r}\text { Roadless } \\
\text { Volume } 1992\end{array}$ & $\begin{array}{r}\text { Unmatched } \\
\text { Matched }\end{array}$ & $\begin{array}{l}8.04 \mathrm{E}+13 \\
8.04 \mathrm{E}+13\end{array}$ & $\begin{array}{l}8.84 \mathrm{E}+13 \\
7.70 \mathrm{E}+13\end{array}$ & $\begin{array}{c}-8.04 \mathrm{E}+12 \\
3.43 \mathrm{E}+12\end{array}$ & $\begin{array}{l}0.010 \\
0.004\end{array}$ & $\begin{array}{l}3.26 \mathrm{E}+13 \\
2.08 \mathrm{E}+13\end{array}$ & $57.36 \%$ \\
\hline
\end{tabular}

Table A12: Results from Primary and Ancillary Analyses, Protected Areas Established in 1990s

\begin{tabular}{lccccccc}
\hline \multirow{2}{*}{ Method } & \multicolumn{3}{c}{ Poverty Index } & & \multicolumn{3}{c}{ NBI } \\
\cline { 2 - 3 } \cline { 7 - 8 } & $\mathrm{Y}(\mathrm{T}=1)$ & $\mathrm{Y}(\mathrm{T}=0)$ & Treatment & & $\mathrm{Y}(\mathrm{T}=1)$ & $\mathrm{Y}(\mathrm{T}=0)$ & Treatment \\
\hline \hline Regression Dropping & $\mathrm{NA}$ & $\mathrm{NA}$ & -0.599 & & $\mathrm{NA}$ & $\mathrm{NA}$ & -4.23 \\
Marginal & {$[32]$} & {$[252]$} & $(0.128)$ & & {$[30]$} & {$[242]$} & $(1.48)$ \\
Post-Match Frequency & $\mathrm{NA}$ & $\mathrm{NA}$ & -0.54 & & $\mathrm{NA}$ & $\mathrm{NA}$ & -1.87 \\
Weighted Regression & {$[32]$} & {$[24]$} & $(0.151)$ & & {$[30]$} & {$[24]$} & $(2.09)$ \\
Genetic Matching & -0.79 & -0.313 & -0.485 & & 79.95 & 85.85 & -5.89 \\
& {$[32]$} & {$[32]$} & $(0.205)$ & & {$[30]$} & {$[30]$} & $(5.38)$ \\
\hline \hline
\end{tabular}

[Number of observations]

(Standard errors) 
Table A13: Balance Results for Analysis Using Protected Areas Established in 1990s- PI

\begin{tabular}{rrcccccc}
\hline Covariate & Status & $\begin{array}{c}\text { Mean } \\
\text { Prot. }\end{array}$ & $\begin{array}{c}\text { Mean } \\
\text { Unprot. }\end{array}$ & $\begin{array}{c}\text { Diff. } \\
\text { in Means }\end{array}$ & $\begin{array}{c}\text { Norm. } \\
\text { Diff. }\end{array}$ & $\begin{array}{c}\text { Mean eQQ } \\
\text { Diff. }{ }^{\ddagger}\end{array}$ & $\begin{array}{c}\text { \%Improve } \\
\text { Mean Diff. }\end{array}$ \\
\hline \hline Poverty Index & Unmatched & 0.552 & 0.744 & -0.192 & 0.056 & 0.329 & \\
\% Forest 1992 1991 & Matched & 0.552 & 0.563 & -0.010 & 0.003 & 0.199 & $94.54 \%$ \\
& Unmatched & 0.510 & 0.194 & 0.316 & 0.534 & 0.316 & \\
Matched & 0.510 & 0.501 & 0.009 & 0.014 & 0.048 & $97.28 \%$ \\
Distance to & Unmatched & 175400 & 108000 & 67370 & 0.314 & 65140 & \\
Average & Matched & 175400 & 145900 & 29480 & 0.123 & 41660 & $56.24 \%$ \\
Elevation & Unatched & 1649 & 2713 & -1065.000 & 0.373 & 1057 & \\
Average Slope & Unmatched & 24.970 & 18.970 & 6.006 & 0.193 & 6.080 & $93.89 \%$ \\
& Matched & 24.970 & 24.890 & 0.087 & 0.003 & 2.305 & $98.56 \%$ \\
Roadless & Unmatched & $3.825 \mathrm{E}+14$ & $8.350 \mathrm{E}+13$ & $2.990 \mathrm{E}+14$ & 0.234 & $2.558 \mathrm{E}+14$ & \\
Volume 1992 & Matched & $3.825 \mathrm{E}+14$ & $2.808 \mathrm{E}+14$ & $1.017 \mathrm{E}+14$ & 0.061 & $1.632 \mathrm{E}+14$ & $65.98 \%$ \\
\hline \hline
\end{tabular}

† Normalized difference in means is the difference in means divided by the square root of the sum of the squared standard deviations of the treated and untreated covariate samples.

¥ Mean eQQ difference is the mean of the raw differences in the empirical quantile-quantile plots.

Table A14: Balance Results for Analysis Using Protected Areas Established in 1990s- NBI

\begin{tabular}{rrcccccc}
\hline Covariate & Status & $\begin{array}{c}\text { Mean } \\
\text { Prot. }\end{array}$ & $\begin{array}{c}\text { Mean } \\
\text { Unprot. }\end{array}$ & $\begin{array}{c}\text { Diff. } \\
\text { in Means }\end{array}$ & $\begin{array}{c}\text { Norm. } \\
\text { Diff. }^{\dagger}\end{array}$ & $\begin{array}{c}\text { Mean eQQ } \\
\text { Diff. }^{\ddagger}\end{array}$ & $\begin{array}{c}\text { \%Improve } \\
\text { Mean Diff. }\end{array}$ \\
\hline \hline NBI 1992 & Unmatched & 89.11 & 91.050 & -1.934 & 0.043 & 1.821 & \\
& Matched & 89.11 & 89.130 & -0.017 & 0.000 & 1.069 & $0.991 \%$ \\
\% Forest 1991 & Unmatched & 0.488 & 0.187 & 0.301 & 0.510 & 0.298 & \\
& Matched & 0.488 & 0.483 & 0.006 & 0.009 & 0.036 & $0.982 \%$ \\
Mistance to & Unmatched & 165600 & 108600 & 57030 & 0.271 & 54590 & \\
Average & Matched & 165600 & 139400 & 26230 & 0.108 & 34620 & $0.540 \%$ \\
Elevation & Matched & 1731 & 2751 & -1021 & 0.360 & 1013 & \\
Average Slope & 1731 & 1746 & -14.74 & 0.006 & 112.6 & $0.986 \%$ \\
& Unmatched & 25.83 & 19.45 & 6.376 & 0.204 & 6.4 & \\
Roadless & Matched & 25.83 & 27.43 & -1.602 & 0.045 & 3.239 & $0.749 \%$ \\
Volume 1992 & Matched & $3.924 \mathrm{E}+14$ & $8.528 \mathrm{E}+13$ & $3.071 \mathrm{E}+14$ & 0.234 & $2.600 \mathrm{E}+14$ & \\
\hline \hline
\end{tabular}

${ }^{\dagger}$ Normalized difference in means is the difference in means divided by the square root of the sum of the squared standard deviations of the treated and untreated covariate samples.

$\ddagger$ Mean eQQ difference is the mean of the raw differences in the empirical quantile-quantile plots. 
Table A15: Regression Results from Primary Specifications

\begin{tabular}{|c|c|c|c|c|}
\hline \multirow[b]{2}{*}{ Covariate/Outcome } & \multicolumn{2}{|c|}{ Standard } & \multicolumn{2}{|c|}{ Post-Match Weighted } \\
\hline & PI & NBI & PI & NBI \\
\hline \multirow[t]{2}{*}{ (Intercept) } & $-2.01^{* * *}$ & $-42.3^{* * *}$ & $-1.42^{* * *}$ & -39.4 \\
\hline & $(0.157)$ & $(3.41)$ & $(0.288)$ & $(6.37)$ \\
\hline \multirow[t]{2}{*}{ Protected } & $-0.535^{* * *}$ & $-5.62^{* * *}$ & $-0.494^{* * *}$ & -2.63 \\
\hline & $(0.099)$ & $(1.2)$ & $(0.106)$ & $(1.7)$ \\
\hline \multirow[t]{2}{*}{ Baseline Poverty } & $0.896^{* * *}$ & $1.26 * * *$ & $0.927 * * *$ & $1.31^{* * *}$ \\
\hline & $(0.017)$ & $(0.0361)$ & $(0.0235)$ & $(0.066)$ \\
\hline \multirow[t]{2}{*}{ Percent Forest 1991} & $0.574^{* *}$ & $6.22^{* * *}$ & -0.0298 & -2.73 \\
\hline & $(0.192)$ & $(2.34)$ & $(0.302)$ & $(4.75)$ \\
\hline \multirow[t]{2}{*}{ Distance to Major City } & $2.77 \mathrm{E}-06^{* * *}$ & $-2.47 \mathrm{E}-05^{* * *}$ & $2.22 \mathrm{E}-06^{* * *}$ & $1.12 \mathrm{E}-05$ \\
\hline & $(4.88 \mathrm{E}-08)$ & $(5.98 \mathrm{E}-06)$ & $(6.33 \mathrm{E}-07)$ & $(9.69 \mathrm{E}-06)$ \\
\hline \multirow[t]{2}{*}{ Average Elevation } & $1.95 \mathrm{E}-04^{* * *}$ & $-0.0035^{* * *}$ & $-4.51 \mathrm{E}-05$ & $6.70 \mathrm{E}-04$ \\
\hline & $(4.39 \mathrm{E}-05)$ & $(0.00054)$ & $(9.09 \mathrm{E}-05)$ & $(0.0014)$ \\
\hline \multirow[t]{2}{*}{ Average Slope } & -0.003 & 0.027 & 0.006 & 0.071 \\
\hline & $(0.0027)$ & $(0.032)$ & $(0.005)$ & $(0.074)$ \\
\hline \multirow[t]{5}{*}{ Roadless Volume } & $2.67 \mathrm{E}-17$ & $1.96 \mathrm{E}-15^{*}$ & $-7.78 \mathrm{E}-17$ & $1.58 \mathrm{E}-15$ \\
\hline & $(9.26 \mathrm{E}-17)$ & $(1.11 \mathrm{E}-15)$ & $(8.29 \mathrm{E}-17$ & $(1.41 \mathrm{E}-15)$ \\
\hline & $\mathrm{R}^{2}=0.918$ & $\mathrm{R}^{2}=0.848$ & $\mathrm{R}^{2}=0.951$ & $\mathrm{R}^{2}=0.845$ \\
\hline & $\mathrm{DF}=300$ & $\mathrm{DF}=287$ & $\mathrm{DF}=89$ & $\mathrm{DF}=83$ \\
\hline & $\mathrm{F}=481$ & $\mathrm{~F}=229$ & $\mathrm{~F}=245$ & $\mathrm{~F}=64.8$ \\
\hline
\end{tabular}

Notes: Outcomes are indicated at column heads and represent 2001 poverty index and NBI. $* * *, * *, *$ Indicate significance at the $0.01,0.05$ and 0.1 level, respectively.

(Standard Errors) 